Louisiana State University

LSU Digital Commons

1995

\title{
Aerobic Fitness and Leisure Physical Activity as Moderators of the Stress-IIlness Relation.
}

Cindy Lynn Carmack

Louisiana State University and Agricultural \& Mechanical College

Follow this and additional works at: https://digitalcommons.Isu.edu/gradschool_disstheses

\section{Recommended Citation}

Carmack, Cindy Lynn, "Aerobic Fitness and Leisure Physical Activity as Moderators of the Stress-IIlness Relation." (1995). LSU Historical Dissertations and Theses. 6084.

https://digitalcommons.Isu.edu/gradschool_disstheses/6084

This Dissertation is brought to you for free and open access by the Graduate School at LSU Digital Commons. It has been accepted for inclusion in LSU Historical Dissertations and Theses by an authorized administrator of LSU Digital Commons. For more information, please contact gradetd@lsu.edu. 


\section{INFORMATION TO USERS}

This manuscript has been reproduced from the microfilm master. UMI films the text directly from the original or copy submitted. Thus, some thesis and dissertation copies are in typewriter face, while others may be from any type of computer printer.

The quality of this reproduction is dependent upon the quality of the copy submitted. Broken or indistinct print, colored or poor quality illustrations and photographs, print bleedthrough, substandard margins, and improper alignment can adversely affect reproduction.

In the unlikely event that the author did not send UMI a complete manuscript and there are missing pages, these will be noted. Also, if unauthorized copyright material had to be removed, a note will indicate the deletion

Oversize materials (e.g., maps, drawings, charts) are reproduced by sectioning the original, beginning at the upper left-hand comer and continuing from left to right in equal sections with small overlaps. Each original is also photographed in one exposure and is included in reduced form at the back of the book.

Photographs included in the original manuscript have been reproduced xerographically in this copy. Higher quality 6" $\times$ 9" black and white photogıaphic prints are available for any photographs or illustrations appearing in this copy for an additional charge. Contact UMI directly to order.

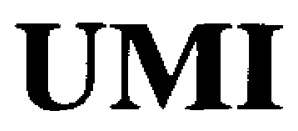

A Bell \& Howell Information Company

300 North Zoeb Road. Ann Arbor MI 48106-1346 USA

$313 / 76 \uparrow-4700 \quad 800 / 521-0600$ 


\title{
AEROBIC FITNESS AND LEISURE PHYSICAL ACTIVITY AS MODERATORS OF THE STRESS-ILLNESS RELATION
}

\author{
A Dissertation \\ Submitted to the Graduate Faculty of the \\ Louisiana State University and \\ Agricultural and Mechanical College \\ in partial fulfillment of the \\ requirements for the degree of \\ Doctor of Philosophy \\ in
}

The Department of Psychology

by

Cindy Lynn Carmack

B.S., Texas A \& M University, 1990

M.A., Louisiana State University, 1993

December, 1995 
UMI Number: 9618274

UMI Microform 9618274

Copyright 1996, by UMI Company. All rights reserved.

This microform edition is protected against unauthorized copylng under Title 17, United States Code.

\section{UMI}

300 North Zeeb Road

Ann Arbor, MI 48103 


\section{ACKNOWI EDGMENTS}

I would like to acknowledge a number of individuals who provided continuous support during the course of this dissertation and throughout my graduate career.

First, I would like to thank my committee members for their guidance and support during the course of this project including Phillip J. Brantley, Ph.D., Mary Lou Kelley, Ph.D., Drew Gouvier, Ph.D., and Steve Morris, Ph.D. A special thanks goes to Dr. Brantley, my major professor, for his continuous support in my academic and professional endeavors.

I would like to thank Edwin Boudreaux for his dedication as a friend and colleague and Marta Amaral-Melendez for her expertise and time committed to this project. I also would like to thank Sheryl Catz for answering my statistical pleas for help and assurance. Additionally, I would like to thank Patricia Dubben, Ph.D., Tom Payne, Ph.D., Phil Godding. Ph.D., and all the other faculty at the Jackson VA/UMC Consortium for their assistance and encouragement throughout this project. Furthermore, I would like to provide a special thanks to Alice Kahle, Alyson McCain, Panela Davis, Christopher Sletten, Kimberly Ujcich, and Samuel Sears for their support through the duration of this project and their individual contributions to a memorable graduate career.

And finally, a special thanks goes to my father for his dedication in supporting my academic career, my mother for her words of encouragement, and my brother, Steve, for his unconditional love. 


\section{TABLE OF CONTENTS}

Acknowledgments $\ldots \ldots \ldots \ldots \ldots \ldots \ldots \ldots \ldots \ldots$ ii

List of Tables $\ldots \ldots \ldots \ldots \ldots \ldots \ldots \ldots \ldots$ iv

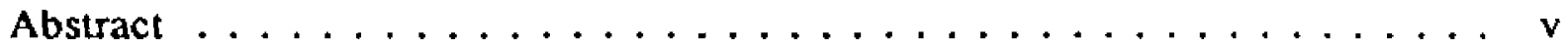

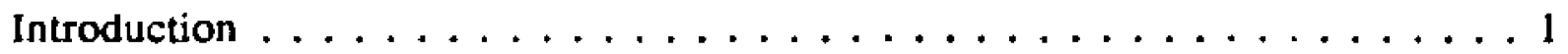

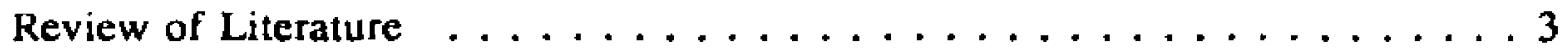

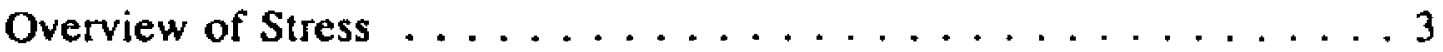

Overview of Major Life Events $\ldots \ldots \ldots \ldots \ldots \ldots \ldots$

Stress and Illness $\ldots \ldots \ldots \ldots \ldots \ldots \ldots \ldots \ldots \ldots$

Stress and Psychopathology . . . . . . . . . . . . . 11

Moderator Variables in the Stress-Illness Relation . . . . . . . 13

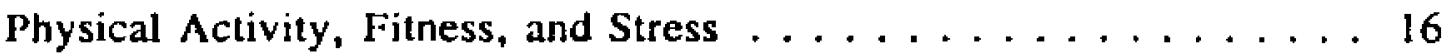

Physical Effects . . . . . . . . . . . . . 17

Psychological Effects ................. 22

Purpose . . . . . . . . . . . . . . . . . 26

Method ............................ 29

Subjects . . . . . . . . . . . . . . . . . 29

Measures . . . . . . . . . . . . . . . . . . . 29

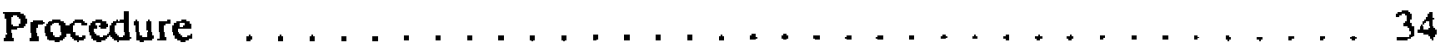

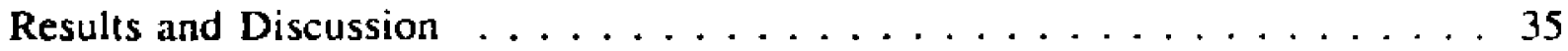

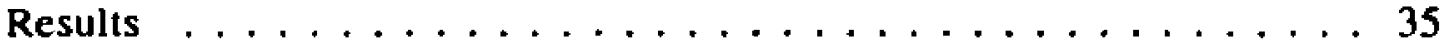

Discussion $\ldots \ldots \ldots \ldots \ldots \ldots \ldots \ldots \ldots \ldots \ldots \ldots$

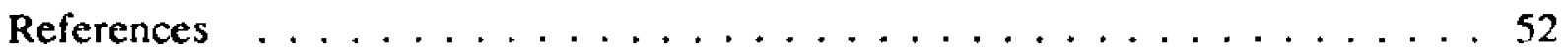

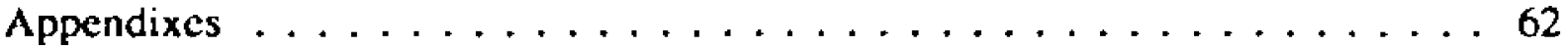

Appendix $A$ : Informed Consent . . . . . . . . . 62

Appendix B: Demographic Questionnaire . . . . . . . 63

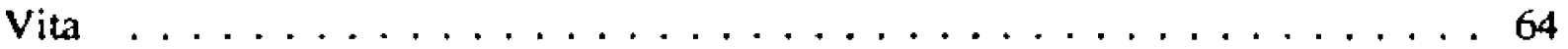




\section{LIST OF TABLES}

1. Simple Statistics: Demographic Variables . . . . . . . . . . . 36

2. Descriptive Statistics on Independent and Dependent Variables . . . . . 37

3. Hierarchical Multiple Regression Examining LES and EVENT . . . . . 40

4. Hierarchical Multiple Regression: SUM as Dependent Variable . . . . . . 41

5. Hierarchical Multiple Regression: TA as Dependent Variable . . . . . . . . 42

6. Hierarchical Multiple Regression: DD as Dependent Variable . . . . . . 44

7. Hierarchical Multiple Regression: Analysis of Main Effects with DD as

Dependent Variable . . . . . . . . . . . . . . . 45 


\begin{abstract}
This study examined exercise as a moderator of the stress-illness relation by exploring leisure physical activity and aerobic fitness as "buffers" of the effects stress has on physical and psychological symptoms in a sample of 135 college students. Specifically, the goal was to provide information regarding the mechanisms by which exercise exhibits its "buffering effects" against minor stress. It was questioned as to whether both increased aerobic fitness associated with exercise and actual participation in the activity itself were necessary for the apparent buffering effects exercise has on stress or is one factor more important than the other.
\end{abstract}

Existing data support the utility of minor life events over major life events in predicting illness. Results of this study were consistent with previous research indicating minor life events provided significant incremental variance above that accounted for by major life events on psychological symptoms including depression and anxiety and physical symptoms report. Major life events no longer predicted physical symptoms once the minor life event variable was entered into the regression equation. Results supported the rationale for examining the moderating effects of exercise on minor life events as opposed to major life events.

Findings suggested a "buffering effect" for leisure physical activity indicating that participants experiencing higher levels of minor stress and engaging in lower levels of physical activity experienced more physical symptoms and anxiety than those with higher stress and higher levels of physical activity. This association was not found with depression. Additionally, there was no apparent moderating effect for 
aerobic fitness on physical or psychological symptoms. Collectively, the data suggested that participating in leisure physical activity as opposed to improving aerobic fitness is the key component to the "buffering effect" of exercise. Results indicated that just as health benefits increase with increased physical activity so do the protective effects against stress. The prescription of increasing physical activity for physical health benefits also may be applied to mental health, and the implications for both are that more individuals can and should participate in regular physical activity. 


\section{INTRODUCTION}

Stress has been implicated in the development of physical and psychological health problems. Research has linked stress with blood glucose levels in Type I diabetes (Halford, Cuddihy, \& Mortimer, 1990) and Type II diabetes (Goetsch, Wiebe, Veltum, \& Van Dorsten, 1990), disease activity in rheumatoid arthritis (Thomason, Brantley, Jones, Dyer, \& Morris, 1992), and psychopathology including depression and anxiety (Hamberger \& Lohr, 1984).

Early research focused on laboratory induced stressors and major life events to ascertain the relation between stress and physical/psychological health. Laboratory studies were criticized for their artificial nature, which prevented the generalizability of their results (Brantley \& Jones, 1993). A variety of criticisms have plagued major life events research including small and weak relations between life events and health outcomes (Lazarus, 1984), and the lack of an established temporal relation between major stress and illness onset (Eckenrode, 1984). Researchers have theorized that minor life events, or ongoing stressors associated with daily living, may be a more important predictor of physical and psychological complaints than major life events. Existing literature has begun to support this hypothesis (e.g., DeLongis, Coyne, Dakof, Folkman, \& Lazarus, 1982; Jandorf, Deblinger, Neale, \& Stone, 1986).

However, not all individuals facing high levels of minor stress develop the same degree of associated physical or psychological symptoms. As a result, research has begun to focus on delineating variables that may determine differential response to stressful stimuli. One method is to examine possible moderators that could "buffer" 
the stress effects. Moderator variables studied that could account for individual differences in the stress-illness relation include social support (Sandler $\&$ Barrera. 1984), self-esteem (DeLongis, Folkman, \& Lazarus, 1988), hardiness (Ouellette. 1993), coping style (Folkman, Lazarus, Gruen, \& DeLongis, 1986), and exercise (Brown \& Lawton, 1986). Exercise is one moderator variable that has only recently been studied and is yielding promising results (Roth \& Holmes, 1985). Despite the fact that exercise has been demonstrated to affect both physical and psychological health, the mechanism by which it exerts its influence has yet to be determined. Researchers have examined both engaging in physical activity specifically leisure physical activity (e.g., Brown \& Lawton, 1986) and having high physical fitness specifically aerobic fitness (e.g., Roth \& Holmes. 1985) in an attempt to demonstrate the "buffering" effect; however. whether both of these components are necessary is inconclusive.

The introduction of this paper provides an overview of stress and examines its relation to physical and psychological health. Next, the literature concerning potential "buffers" in the stress-health relation is explored with a particular focus on physical activity and physical fitness. In the final section, a study is presented which examined how leisure physical activity and aerobic fitness moderate the association minor stress has with physical symptoms and mood. 


\section{REVIEW OF LITERATURE}

\section{Overview of Stress}

Research has demonstrated that stress can adversely affect an individual's physical and emotional well-being. Unfortunately, a lack of an agreed upon definition of stress may obstruct a thorough understanding of the stress-health relation (Spielberger, 1987; Engel, 1985). The three current conceptualizations of stress are response models, stimulus models, and interaction models (Lazarus \& Folkman. $1984)$.

Hans Selye (1993), in earlier research, coined the term "stress" and was a forerunner in recognizing its effects on the body. He provided a good example of a response definition and described stress as the "nonspecific, or common, result of any demand upon the body, be the effect mental or somatic". He observed a stereotyped pattern of physiological changes across individuals in response to a variety of situations. He labeled this prototypical response the general adaptation syndrome and postulated it consisted of three phases: alarm, resistance, and exhaustion, all of which are associated with specific physiological changes. Response oriented theorists acknowledge the existence of stressors, or the agents that activate the patterned response; however, they focus on the mechanisms of the response in an effort to understand its relation to illness.

Characteristic physiological changes occurring in response to stress have been identified. Patterns of cardiovascular and neuroendocrine responses occur in an effort to help the body adapt to environmental change (Selye, 1993). Cardiovascular 
changes include increases in systolic and diastolic blood pressure as well as increases in heart rate (see Katkin, Dermit \& Wine, 1993, for review), decreases in preejection period (e.g.,Kamarck, Jennings, Stewart, \& Eddy, 1993), and decreases in stroke volume (e.g., Kasprowicz, Manuck, Malkoff, \& Krantz, 1990). Additionally, hormonal changes including increases in plasma norepinephrine (e.g., Dimsdale, Young, Moore, \& Strauss, 1987) and epinephrine (e.g., Dimsdale \& Moss, 1980), as well as changes in the immune system (see Stein \& Miller, 1993 for review; O'Leary. 1990) are observed.

Not all response theorists agree with Selye's conceptualization of the stress response and have argued that the response may vary as a result of the nature of the stimulus and individual differences (Everly, 1987). In support of this line of thinking and in contrast to Selye's theory, individual differences in physiological reactivity to stress have been well documented as researchers have identified "high" versus "low" reactors in response to laboratory induced stressors (e.g., Kasprowicz, et al.. 1990; Krantz \& Manuck, 1984). Psychometric studies assessing the reliability of these individual differences in cardiovascular reactivity have yielded positive results (Kamarck, et al., 1993; Saab, Llabre, Hurwitz, Frame, Reineke, Fins, McCalla, Cieply, \& Schneiderman, 1992; Kasprowicz, et al., 1990). As a result, studies have attempted to examine variables accounting for differential response to stressful stimuli and have looked for ways to attenuate the stress response in those identified as "high" reactors. 
The stimulus-oriented model is the most common conceptualization of stress where the focus of attention is on the stressor as opposed to the response (Lazarus \& Folkman, 1984). Theorists who define stress as a stimulus focus on stressful environmental events (Dohrenwend \& Dohrenwend, 1974) that researchers agree falt into one of three categories: catastrophic events affecting a large number of persons. major life events affecting one or a few persons, and daily hassles (Lazarus \& Folkman, 1984). A variety of inventories have been developed to measure these events including the Life Events Survey (LES) (Sarason, Johnson, \& Siegel, 1978) for major life events and the Weekly Stress Inventory (WSI) (Brantley, Jones, Boudreaux. $\&$ Catz, in press) for minor life events.

Critics of the stimulus model argue against the failure to consider individual differences in cognitive appraisal and coping mechanisms that result in differential response to stressful stimuli (Lazarus \& Folkman, 1984). They reason that there are individual differences in the perceptions of situations as stressful or desirable. As a result, life events measures following a stimulus-oriented model have included ratings on the impact of these events, thereby addressing the problem of individual differences in stress perception. The LES and the WSI are examples of such improved scales.

Interactional models acknowledge these individual differences and define stress by examining the relation between organism and environment. They critique the unidimensionality of strictly studying stressors or stress responses (Lazarus, 1993). Interactional theorists argue these pure models overlook important moderating 
variables that account for individual differences (Derogatis \& Coons, 1993). Lazarus and Folkman (1984) proposed such a relational model and explained stress as a specific relationship between person and environment, which the person appraises as exceeding his/her available coping resources and threatening his/her well-being. According to this model, an individual's reaction to his/her environment depends on the external event itself and the appraisal of the particular circumstances, which accounts for variable responses to stressful stimuli.

\section{Overview of Major Life Events}

Early research focused on the impact of major life events, such as bereavement or natural disaster, on physical and psychological symptoms in an attempt to examine the effect of stress on illness. Creed (1985) reviewed the early literature concerning the life events and physical illness relation and determined the research findings are inconclusive and many of the studies contain methodological flaws. He noted that the studies finding a relation only found small positive correlations between stress and illness. He concluded that behavioral and biological influences in addition to life events could help explain the stress-illness relation. DeLongis, et al., (1982) reported similar problems with major life events research noting psychometric problems with many studies. They criticized early major life events research for strictly following the stimulus-oriented model and failing to consider individual differences in appraisal and available coping resources. Later, major life events measures such as the LES (Sarason, et al., 1978) incorporated appraisal by allowing for ratings. 
Another criticism concerns the infrequent nature of major life events. First, a temporal relation between major life events and the onset or fluctuations in disorders is difficult to establish (Brantley \& Jones, 1993). This idea sparked the early rationale for the study of minor life events by Kanner, Coyne, Schaefer, and Lazanus (1981). These researchers hypothesized that minor stressors are a "more proximal measure of stress"; and therefore, they may have a stronger relation to symptoms. Additionally, it has been postulated that this episodic nature of major life events may not be as important as chronic stress. Selye's model supports the emphasis on chronic stress with the end result being exhaustion when the demand is of sufficient intensity and duration (Selye, 1993). Eckenrode (1984) postulated that one way to conceptualize chronic stress is as an accumulation of daily stressors. As a result of these criticisms, researchers have theorized that minor life events, or the ongoing stresses associated with daily living, may be as important a predictor of physical and psychological complaints as major life events.

Although major stress alone appears to insufficiently explain health status, its study in the stress-illness relation should not be underemphasized. More recent major life events studies have attempted to overcome some of their criticisms by examining moderator variables to address individual differences, and exploring their relation to minor life events. Weinberger, Hiner, and Tierney (1987) proposed that major life events affect health status indirectly by increasing the frequency and intensity of daily hassles. This hypothesis was based on the fact that subjects in their study reporting more major life events at the baseline phase also reported more hassles during the 
following 6 months. Additionally, Delongis et al. (1982) proposed that hassles serve as a mediating variable through which major life events affect health. Rowlinson and Felner (1988) argue that both major life events and minor stressors are conceptually distinct and contribute independently to stress response.

\section{Stress and Illness}

Despite disagreements in the stress definition, research consistently has reported stress as contributing to health problems such as insomnia, headaches, elevated blood pressure, and coronary heart disease (Spielberger, 1987). Various mechanisms by which stress exerts its influence on illness have been hypothesized. The most extensively studied hypothesis is based on the idea that specific physiological responses to stress may be involved in the etiology of various physical disorders. Most of these studies have focused on variables thought to be related to coronary heart disease (Herd, 1986; Cinciripini, 1986b) and essential hypertension (Katkin, Dermit, \& Wine, 1993; Cinc:-ipini, 1986a). These researchers hypothesized that prolonged and exaggerated cardiovascular and endocrine responses to stressors influence the development of these disorders (Manuck \& Krantz, 1986). For example, chronic hemodynamic changes such as increased pulse rate and arterial pressure are thought to contribute to the development of atherosclerosis (see Clarkson, Manuck, \& Kaplan, 1986, for review). Increased plasma catecholamines also may contribute by facilitating plaque accumulation in the arteries (Katkin et al., 1993). Additionally, stress is thought to be involved in the etiology of disease due to its 
potentially suppressive effects on immune functioning; however, this area of research is relatively new, and results are not definitive (see Stein \& Miller, 1993, for review).

Research supports the idea that stress is related to health status. DeLongis, et al. (1982) examined the association of both major life events and daily hassles with somatic health. Results indicated minor life events accounted for a significant amount of variance in health status and somatic symptoms. Hassles remained significantly related to somatic illness even after controlling for the effects of major life events. There was a small positive relation between life events and somatic illness. Jandorf, et al., (1986) replicated this study and found similar results. Undesirable daily events were better predictors of somatic symptoms than the number of major life events and than desirable events.

The impact of minor stress on somatic symptoms also has been studied in specific medical populations and have obtained similar results (see Brantley \& Jones, 1993, for review). Thomason, et al., (1992) found daily minor stress to account for a significant amount of variance in inflammation level in a sample of rheumatoid arthritis patients. This effect was maintained even when controlling for major stress and disease severity. No relation was found between major stress and disease status. Likewise, daily stress was found to be significantly correlated with both physical and psychological disability as well as pain in a sample of low-income elderly patients with osteoarthritis (Weinberger, et al., 1987). As in the previous study, this result was maintained even after controlling for the effects of major life events. When controlling for hassles, there was no significant correlation between these variables 
and major life events. The researchers concluded that hassles may be more salient due to their proximal nature. Additionally, daily stress has been found to be associated with symptom severity in asthmatic and COPD patients (Goreczny, Brantley, Buss, \& Waters, 1988). Significant differences in symptoms such as amount of coughing, amount of wheezing, activity restriction, and interference with daily routine were found between high and low stress days. Nathan, Brantley. Goreczny, and Jones (1988) replicated this study in a sample of purely asthmatic patients and obtained similar results. Studies also have implicated minor life events in headache activity in both muscle-contraction (Mosley, Penzien, Johnson, Brantley, Wittrock, Andrew, \& Payne, 1991) and migraine headache sufferers (Mosley, et al., 1991; Levor, Cohen, Naliboff, McArthur, \& Heuser, 1986).

Studies examining the effect of stress on illness have supported the notion that minor life events have greater predictive utility than major life events in accounting for physical health. Additionally, minor stress has been implicated in the exacerbation of several medical disorders. However, researchers have noted that not all persons with medical disorders experience an exacerbation in their symptoms following the occurrence of minor stressful events (Garrett, Brantley, Jones, \& McKnight, 1991; Mosley, et al., 1991; Goetsch, et al., 1990; Brantley \& Jones. 1993). These findings have further validated the need to explore possible moderators that could account for individual differences in response to minor life events. 
Stress and Psychopathology

Stress also has been implicated in the development of psychological problems such as anxiety and depression. Research findings with stress and anxiety disorders have been limited, which is thought to be due in part to continuous changes in diagnostic criteria. Much of what is known to date is based on clinical reports. Additionally, a temporal relation between stress and phobic disorders, in particular, is often difficult to establish because of disparity between illness onset and presentation for treatment or research participation (Rabkin, 1993).

The most thoroughly investigated psychiatric disorder in the stress literature is depression (Rabkin, 1993). Various psychological and physiological mechanisms linking stress to depression have been proposed. One psychological hypothesis states that stress may result in a decrease in self-esteem or self-efficacy (Holmes, 1993). Self-efficacy refers to people's beliefs in their abilities to exercise control over events in their lives. A perception of self-inefficacy to attain goals can result in depression (Bandura, 1989). One commonly studied biological theory of depression is the catecholamine hypothesis. This theory is based on research identifying changes in noradrenergic receptor sensitivity in the brain as well as decreases in MHPG, a metabolite of norepinephrine, in the urine of depressed patients. Additionally, depressed patients often respond to medications that block the reuptake of norepinephrine (see Potter, Grossman, \& Rudorfer, 1993 for review). Likewise, stress results in changes in catecholamine response, and depressed patients have been found to have disturbances in the systems associated with the stress response (see 
Gruen, 1993, for review). Other theories of depression have been proposed but are beyond the scope of this review.

Until recently, as with stress and illness, stress and depression were studied within the context of major life events. Billings and Moos (1982) found a significant correlation between negative life events and depression in a sample of community men and women. This effect was maintained even after controlling for sex. Similar results were found in a sample of adolescents with major life events significantly related to negative affect. Both life event frequency and life event impact were found to significantly predict negative affect with no significant difference in their predictive utility (Rowlinson \& Felner, 1988). In a 4 month longitudinal study, previous month's life events were found to be related to depression even when controlling for prior levels of depression (Hammen, Mayol, deMayo, \& Marks, 1986).

Because of the limitations of major life events research, depression also has been studied within the context of minor life events. An early study by Kanner et al., (1981) found number of hassles to be significantly related to psychological symptomatology. Hassles remained a significant predictor of symptoms even after controlling for the effects of major life events. The authors argued minor stressors to be a more proximal measure of stress than life events, which would make them more related to symptoms. Likewise, Rowlinson and Felner (1988) found daily hassles significantly related to negative affect even after the effects of major life events had been statistically removed. Further support was demonstrated by Eckenrode (1984) who found one of the most important predictors of mood in a sample of 96 women to 
be daily stress; whereas, major life events did not significantly predict mood. In a path analysis model of examining determinants of mood, major life events were found to indirectly affect mood through their influence on other variables including daily stress. The author postulated major stressors to be effective in altering daily occurrences, which in turn, affected daily mood. Bolger, DeLongis, Kessler, and Schilling (1989) obtained similar results with daily stressors accounting for $20 \%$ of the variance in mood.

In sum, the study of minor life events has enhanced the stress literature in that it has been shown to be a more important predictor of physical and psychological complaints than major life events. Minor life events researchers are now turning their focus to examine variables that may account for differential response to minor stressful stimuli.

Moderator Variables in the Stress-Illness Relation

Researchers have begun to examine individual differences in response to stress by exploring moderators that could "buffer" the stress effects; thereby, accounting for variable responses to stressful stimuli. A moderator is a variable that affects the direction or strength of the relation between an independent and dependent variable (Baron \& Kenny, 1986). There is interest in identifying variables which attenuate the impact of stress, as opposed to those which directly influence criterion variables independent of stress severity (Billings \& Moos, 1984). Moderator variables frequently studied include coping (Moos \& Schaefer, 1993: Folkman, et al., 1986), self-esteem (DeLongis, et al., Lazarus, 1988) and social support. Exercise (Roth \& 
Holmes, 1985) is a moderator variable that is less frequently studied and will be reviewed in the next section.

The most commonly studied moderator variable is social support (Blaney, 1985) and as a result, will be the focus of this discussion. To date, no agreed upon definition of social support exists; however, three areas have been identified as components of the social support construct: suppon networks, supportive behavior, and subjective appraisal of support (see Hobfoll \& Vaux, 1993 for review).

Researchers have examined the "buffering" effect as well as the direct effect of social support on stress response. Research focusing on the "buffering hypothesis" postulates that high levels of support are effective in reducing stress effects for persons under high levels of stress. Social support has no effect on those under low levels of stress (Cohen \& Hoberman, 1983; Sandler \& Barrera, 1984). One proposed mechanism by which social support reduces stress is by providing the individual access to "emotional, intellectual and even material assistance" when experiencing stress (Blaney, 1985). In a review, Cohen and Wills (1985) provided evidence that social support "buffers" the effects major stress has on both physical and psychological well-being. Sandler and Barrera (1984) found a stress-buffering effect for support satisfaction, an aspect of social support, on psychological symptomatology. Additionally, results indicated a "buffering effect" of received social support on anxiety.

Furthermore, the "buffering effect" of social support has been studied within the context of minor life events. Delongis, et al. (1988) examined individual 
differences, including social support, in the extent to which daily hassles were associated with physical symptoms and mood in a sample of 75 married couples.

From the results, the authors concluded social support was a moderator of stress because the relation between daily stress and illness was lower in subjects with high support. Additionally, they found the role of social support to be greater in the minor stress-mood relation than in the minor stress-illness relation. Additional support for the "buffering" role of social support was obtained by Caspi, Bolger, and Eckenrode (1987). These researchers examined stress and mood in 96 women over 28 consecutive days. Results indicated a moderating effect of social support that occurred on subsequent day's mood.

Research also has obtained positive results with regards to the direct effect of social support on physical and psychological well-being (Cohen \& Wills. 1985; Sandler \& Barerra, 1984). These results may indicate that low levels of support actually result in depression or that being depressed influences the amount of support received (see Blaney, 1985, for review). Perceived social support was found to significantly predict depressive symptomatology in a heterogenous population of HIV + patients. Results failed to support the buffering hypothesis (McClure, Thomason, Catz, Jones, \& Brantley, 1993). Lin, Simeone, Ensel, and Kuo (1979) found social support to have a direct effect on psychiatric symptoms as it accounted for a significant amount of the variance in psychiatric symptoms; however, their data did not support the "buffering" hypothesis. Similar studies have obtained comparable results (for reviews see Hobfoll \& Vaux, 1993). The results of these studies may 
suggest that for some group of individuals, social support works independent of the severity of the stressors to which an individual is exposed, as opposed to "buffers" which attenuate the effects of suress.

Overall, studies examining the "buffering hypothesis" of social support have provided mixed results (for reviews see Hobfoll \& Vaux, 1993; Blaney, 1985). Perhaps the precise mechanism by which social support exerts its effects varies with individuals. Additionally, the individual variation in the "buffering" effect of social support may be due to other variables which could be moderating the stress-illness relation.

Physical Activity, Fitness, and Stress

Physical activity and physical fitness are becoming more frequently studied as potential moderators in the stress-illness relation. Physical activity can be defined as "bodily movement accomplished by muscle power and the expenditure of energy". Physical fitness, on the other hand, refers to "a set of attributes that represent the capacity to perform the physical activity" and encompasses all systems in the body influenced by physical activity (Paffenbarger, Hyde, \& Wing, 1990). Physical fitness is determined by both physical activity and genetic factors (Bouchard, 1990), and typically can be improved in adults by $15-20 \%$ with aerobic exercise training (ACSM. 1988). It is necessary to examine the influence of both variables as potential buffers. as studies to date have found the correlation between physical fitness and physical activity to typically be around 0.3-0.5 (Paffenbarger, Blair, Lee, \& Hyde, 1993). 
The use of exercise as a stress management technique is based on the idea that long-term aerobic training results in cardiovascular (CV) and sympathetic nervous system (SNS) adaptations. $\mathrm{CV}$ and SNS responses to the physical stress of exercise are attenuated after prolonged training. Given the similarities in physiological response to exercise and stress, researchers have postulated the CV and SNS responses to behavioral stress also would diminish following improvements in fitness level (Claytor, 1991; Holmes \& Roth, 1985). Results have not thoroughly supported this "fitness hypothesis"; therefore, researchers have questioned whether fitness is the key to the benefits of exercise, especially with regards to its psychological effects. The literature reviewing the physical and psychological benefits of physical activity and physical fitness will be examined next.

\section{Physical Effects}

Most studies exploring the stress-buffering effects of exercise have examined whether aerobic fitness affects response to and recovery from laboratory-induced psychosocial stressors. For the most part, cardiovascular responses including hear rate, blood pressure response, and cardiac output, as well as catecholamine responses have been examined (Sothmann, 1991). Results of these studies have yielded contradictory evidence regarding cardiovascular response to and recovery from acute stress, including both novel and familiar stressors.

Holmes and Roth (1985) found high-fit subjects to display a smaller increase in pulse rate in response to a mildly stressful novel task than did low-fit subjects even when controlling for baseline differences. On the other hand, Sinyor, Schwartz, 
Peronnet, Brisson, and Seraganian (1983) found the differences between high-fit aerobically trained and untrained individuals in heart rate were in the recovery phase as trained subjects returned more quickly to baseline. Other researchers also have found no differences in heart rate responses to novel stressors (Claytor, 1991; Cox, 1991).

Claytor (1991) hypothesized that there would be a clear differentiation in $\mathrm{CV}$ and SNS responses between high-fit aerobically trained and untrained individuals when presented with familiar stressors as opposed to novel stressors. He found significant differences between trained and untrained subjects in CV response to familiar stimuli. Trained subjects displayed reduced mean anterial pressure and cardiac output responses. Since no significant differences were found in heart rate response, reduced cardiac output responses are a product of reduced stroke volume. Results suggested that researchers finding no differences in heart rate response should measure other indicators of cardiovascular response in addition to heart rate.

Studies examining CV fitness and catecholamine response to acute stress also have yielded contradictory results. Some studies have found no significant differences between fit and unfit subjects in the magnitude of $\mathrm{CA}$ (catecholamine) response to novel stressors (Hull, Young, \& Ziegler, 1984; Sinyor et al., 1983). However, Sinyor et al. (1983) did find that CV fit subjects reached peak norepinephrine (NE) levels earlier in the psychosocial stress protocol than low-fit subjects. Cox's (1991) review of his rat studies examining differences in trained and untrained rats indicated no differences in plasma catecholamine levels in response to novel stressors. 
When subjects were exposed to a familiar stressor, a well-learned vigilance task, Sothmann, Horn, Hart, and Gustafson (1987) found an increased norephinephrine response in low-fit subjects as compared to high-fit subjects. They found the high-fit subjects to exhibit stable plasma norepinephrine from a 30 minute baseline period to the end of the vigilance task; whereas, the low-fit subjects showed variability across the collection period with consistency of responses within this group. It should be noted that the subjects in this study were screened based on selfreport measures of trait anxiety. Only high trait anxious subjects were used to ensure reactivity to the stress condition. The researchers note this restriction limits the generalizations of their results. Sothmann et al. (1991) noted that low-fit subjects in their study had an extremely low VO2max and that higher plasma norepinephrine responses may have reflected deconditioning. In support of this idea, Claytor (1991) reported no significant differences between trained and untrained individuals with regards to norepinephrine response during exposure to a familiar stressor.

It seems questionable that the level of stress evoked in the laboratory could be comparable to that elicited in the natural environment; thereby affecting the generalizability of the results. Cox (1991) debated whether the laboratory stressors are of sufficient emotional intensity to elicit physiological responses large enough for the detection of group differences. Some of the studies discussed in this review selected subjects who would be most likely to respond to the stressors employed. Unfortunately, this also limits the generalizability of the results. 
Studies examining real life stressors overcome the limitations imposed by laboratory studies; however, few studies have actually been conducted outside the laboratory. Research implies physical fitness can moderate the effects that major stress has on physical well-being. Roth and Holmes (1985) found a significant stress by fitness interaction in a sample of undergraduate students for the outcome variable health problem severity, which referred to the degree to which the health problem interfered with normal activities. Stressful life events occurring the preceding year were related to subsequent poor physical health in low-fit subjects. Major stress was found to have little effect on the physical health of high-fit subjects. This study did not examine physical activity; therefore, the degree to which physical fitness was actually the key component in the "buffering" effect could not be determined, i.e., it could have been that the more fit were more active.

Like physical fitness, little research has examined the moderating role of exercise habits or physical activity on physical symptoms. Brown and Lawton (1986) obtained a significant stress by exercise interaction in a group of adolescent females. Further analysis indicated significant differences on an illness measure between high and low stressed groups who exercised infrequently. No significant differences were found between high and low stressed groups who exercised regularly, indicating major life events have a greater impact on those who do not exercise regularly than those who do. A similar study obtained comparable results (Brown \& Siegel, 1988). Results lend support to the premise that engaging in physical activity is the key variable; however, since fitness also was not measured and controlled for, definitive 
statements regarding the necessity and sufficiency of physical activity can not be made.

One study could be located that examined both aerobic fitness and leisure physical activity as moderating the physical effects of major life events. Brown (1991) conducted a study examining the stress buffering effect of aerobic fitness and leisure physical activity as measured by self-reported exercise on illness in college students. Illness was measured by both self-report, which was assessed with an illness checklist, and visits to a health center, which was assessed through analysis of health center records. Results indicated a significant stress by fitness interaction for both outcome measures. There also was a significant stress by exercise interaction for the outcome variable self-reported illness. The authors failed to discuss the stress by exercise interaction since the effect was lost after controlling for psychological distress. They concluded that major life events were more strongly linked to poor health status among those with low physical fitness levels than among those with high levels. This study examined both aerobic fitness and leisure physical activity; however, they were examined in separate regression analyses, which prevented conclusions regarding their unique contributions to predicting health status from being determined.

Furthermore, no studies could be found examining aerobic fitness and/or leisure physical activity as moderating the effects minor life events has on physical symptoms. 


\section{Psycholorical Effects}

Exercise therapy has been incorporated in the treatment of various mental health disorders including anxiety (Long \& Haney, 1988) and depression (Simons, McGowan, Epstein, Kupfer, \& Robertson, 1985). It has just been within the past few decades that the idea of exercise preventing or treating mental health problems has been explored.

Recently, aerobic exercise has gained attention as a treatment for depression. A 1983 survey of nearly 2000 primary-care physicians revealed that $85 \%$ regularly prescribed exercise for depressed patients (Morgan \& Goldston, 1987). Simons, et al. (1985) reviewed the literature on the effects of exercise on mood states in clinically depressed populations. He found that in clinical populations exercise therapy led to significant improvements in depression comparable to those seen with standard psychotherapy. Similar results have been obtained in a sample of 15 moderately depressed individuals who engaged in a ten-week exercise program. At program completion, subjects failed to show changes in fitness level, but their depression scores on a self-report measure significantly decreased, and these effects were maintained at a 21-month follow-up (Sime, 1987). Other researchers have found similar results and have suggested integrating a physical fitness program into treatment plans for depressed patients (e.g., Martinsen, Strand, Paulsson, \& Kaggestad, 1989).

Both biological and psychological hypotheses have been postulated concerning the antidepressant effects of exercise. The physiological explanation is based on 
increases in physical fitness and associated physiological changes. Those who suppon this theory argue that decreased cardiovascular response to physical stress may be related to decreased responses to emotional stress, thereby preventing depressive reactions in response to stress. This "fitness" hypothesis requires the individual to exercise at least 9-10 weeks to achieve the effect (Simons, et al., 1985). The problem with this theory, however, is that fitness and depression do not correlate consistently. For example, Sime (1987) found no changes in fitness level after exercise training. but significant alleviations in depressive symptomatology. Lawrence (1983) reponed that patients may show a decrease in depressive symptoms in a minimum of three weeks. As a result, researchers are questioning the sufficiency of physical fitness to explain the improvement in depression associated with exercise.

Cognitive theories concerning the antidepressant effect of exercise are based on Bandura's self-efficacy theory (1977). Supporters of this hypothesis suggest exercise therapy is effective because it provides the individual with a sense of self-efficacy by allowing the individual to master experiences (Simons, et al., 1985). These mastered experiences could be associated with engaging in the activity itself or improvements in fitness level resulting in increased functional capacity. This theory corresponds with the idea that both being physical activity and physical fitness could be important in moderating stress effects. Sinyor, Golden, Steinert, and Seraganian (1986) examined the effects of exercise on self-mastery in a nonclinical population. After ten weeks of training, only the aerobic exercise group. as compared to an anaerobic exercise group and a wait-list control group, showed improvements in fitness and increases in self- 
mastery. However, because fitness improvements also were obtained, the mechanism by which changes in perceived self-mastery occurred could be by either engaging in physical activity or by the improvements in fitness.

Aerobic exercise also has been used as a form of treatment for anxiety. particularly state anxiety. Morgan (1987) conducted a series of studies investigating the effects of aerobic and anaerobic exercise on state anxiety in normal subjects. His results indicated that light to moderate exercise does not reduce state anxiety. On the other hand, significant reductions in state anxiety follow high intensity exercise. This anxiety reduction lasted for approximately 2-4 hours following exercise. Dishman (1985) reported similar findings in a literature review of the effects of exercise on state anxiety. Studies suggest the effects of exercise on state anxiety are short-term (Berger, Friedmann, \& Eaton, 1988; Dishman, 1985).

Studies also have compared exercise to other anxiety reducing techniques. Morgan (1987) evaluated the state anxiety of individuals in a nonclinical population. He compared acute physical activity with "time-out" therapy, where the individual rested quietly in a sound-proof room, and meditation. Results showed equivalent effects across the three treatment modalities; however, the exercise effects tended to persist for a longer period of time.

Researchers have proposed various hypotheses concerning the tranquilizing effects of exercise. Biological theorists suggest the increase in circulating catecholamines, or the rise in brain temperature following aerobic exercise result in a relaxed state (deVries, 1987). Behavioral theorists suggest the anxiety reducing effect 
of exercise are a result of distraction from stressful stimuli (Morgan, 1987).

Likewise, Dishman (1985) suggested that exercise could be used as distraction from daily events or thoughts eliciting an anxiety response. These theories also identify engaging in physical activity as the key component to the effects of exercise.

Little research has actually examined the moderating effects of physical fitness and/or physical activity on psychological variables. Roth and Holmes (1985) examined fitness as a moderator of major life events on depression and anxiety. Results indicated a trend for a stress by fitness interaction on depression, but results were not significant. Trait anxiety was not predicted by fitness or the stress by fitness interaction. Brown and Lawton (1986) examined the moderating role of physical exercise on mood in a sample of female adolescents. Results indicated a significant major life stress by exercise interaction. Post hoc analyses indicated persons under high stress who engaged in low levels of exercise had significantly greater scores on a measure of negative affect. No significant difference existed between high and low stress subjects who engaged in high levels of exercise.

As in studies examining physical activity and physical fitness as moderating the physical effects of major life events, no studies could be located that simultaneously studied both variables as moderating the psychological effects of major life events. Furthermore, no studies could be found examining physical activity and/or physical fitness as moderating the effect minor life events has on mood.

Most of the research on physical activity, physical fitness, and psychological symptoms has been from a treatment intervention perspective. Unfortunately, 
Sothmann et al., (1991) noted in a review of the longitudinal studies that despite improvements in aerobic fitness, the fitness levels are lower than those seen in highfit subjects in cross-sectional studies. As a result, it may not be possible to demonstrate a true "fitness" effect following an exercise intervention. Kubitz and Landers (1993) reported similar problems and argued that longitudinal studies have examined small to moderate differences in fitness; however, a large variability in fitness is necessary to detect differences in reactivity. One way of studying the "fitness" hypothesis and ensuring variability in fitness levels is through a crosssectional analysis. Further study is necessary to determine the role of physical fitness and physical activity in psychological health. It may be that fitness is not the key component in psychological health. and that changes following exercise are a result of engaging in physical activity.

\section{Purpose}

The literature implicates stress in the development and exacerbation of physical and psychological health problems. Specifically. minor life events have been shown to predict more variance in both physical and psychological symptoms than major life events (e.g., DeLongis, et al., 1982; Jandorf, et al., 1986). Research has now turned its focus to examining differences in individual response to stress by studying potential moderator variables, or possible factors that could attenuate the stress response. Exercise has been a less frequently studied moderator variable.

Research has demonstrated that exercise can effect both physical and psychological health. However, the specific mechanism by which exercise exerts its 
influence remains inconclusive. Both physical activity and physical fitness have been hypothesized as key components; however, whether they are both necessary for the "buffering" effect on stress is inconclusive.

Recently, studies have examined the moderator role of physical activity and fitness on physical and psychological response to major life events. The limited data available indicate results are positive with regards to the "buffering effect" of fitness on physical symptoms, but its effect on psychological health remains inconclusive. Additionally, there have been few studies examining physical activity; however, results appear positive regarding its effect on both physical and psychological symptoms. No studies have been conducted examining the moderating role of physical fitness or physical activity in response to minor stress.

The present study simultaneously examined aerobic fitness and leisure physical activity as moderators affecting the relation between minor stress and stress response including mood and physical symptoms report. During the course of the study, the following questions were addressed:

1. Does minor stress add significant variance to the prediction of mood above that accounted for by major life events? Given the data supporting the greater predictive utility of minor life events over major life events (e.g., DeLongis, et al., 1982), it was hypothesized that minor life events would account for significant incremental variance in mood over that accounted for by major life events.

2. Does minor stress add significant variance to the prediction of physical symptoms above that accounted for by major life events? Given the data supporting 
the greater predictive utility of minor life events over major life events (Jandorf, et al., 1986), it was hypothesized that minor life events would account for incremental variance in physical symptoms above that accounted for by major life events.

3. After controlling for the effects of major life events, does aerobic fitness moderate the effects minor stress has on physical symptom report? It was hypothesized that there would be a significant minor stress by physical fitness interaction such that those experiencing increased levels of minor stress and exhibiting decreased fitness levels would experience increased physical symptoms.

4. After controlling for the effects of major life events, does leisure physical activity moderate the effects minor stress has on physical symptom report? It was hypothesized there would be a significant minor stress by physical activity interaction such that those experiencing increased levels of stress and engaging in decreased levels of physical activity would experience increased physical symptoms.

5. After controlling for the effects of major life events, does leisure physical activity moderate the effects minor stress has on mood? It was hypothesized that there will be a significant minor stress by physical activity interaction such that those experiencing increased levels of minor stress and engaging in decreased levels of physical activity would exhibit more negative mood scores.

6. After controlling for the effects of major life events, does aerobic fitness moderate the effects minor stress has on mood? Given that the literature has provided mixed results regarding the effects of fitness on mood, there was no a priori hypothesis with regards to the moderating effect physical fitness would have on mood. 


\section{METHOD}

Subjects

One hundred-thirty-five volunteers were recruited from undergraduate classes

at Louisiana State University. All subjects signed an informed consent, explaining the purpose of the study (see Appendix A). Subjects received a "fitness evaluation" as compensation for participation in this study including results from aerobic capacity test, stretch test, caliber test, and muscular strength and endurance test, as well as recommendations regarding physical activity to improve physical fitness.

Additionally, subjects received extra credit in their psychology or kinesiology course for participation.

Measures

Weckly Stress Inventory (WSI). The WSI (Brantley, Jones, Boudreaux, \& Catz, in press) is an 87-item self-repon inventory modelled after the Daily Stress Inventory (DSI) (Brantley, Waggoner, Jones, \& Rappaport., 1987) that assesses minor stressful events that might have occurred over the past week. Subjects rate each item on a 7-point Likert-type scale indicating how stressful they perceive the event, ranging from $1=$ "occurred but was not stressful" to $7=$ "caused me to panic". The WSI yields three basic scores: 1.) EVENT score which is the number of items endorsed; 2) IMPACT score which is the sum of the subjective ratings of each item; 3) AVERAGE IMPACT score which is the average of the ratings assigned to the endorsed items, calculated by dividing the Impact score by the Event score. The WSI has good internal consistency with coefficient alphas of .96 for EVENT and .97 for 
IMPACT, as well as adequate test-retest reliability (.60). Pilot studies have shown convergent validity with another measure of minor stress, the Hassles Scale (Kanner. et al., 1981). The correlation between the Event score on the WSI and the sum score on the Hassles Scale was .61.

Life Experiences Survey (LES). The LES (Sarason, et al., 1978) is a 50-item self-report questionnaire assessing major life events occurring over the past 12 months. Responders assign positive or negative weightings to each event from $-3=$ "extremely negative" to $+3=$ "extremely positive". Three composite scores are obtained: 1) TOTAL = total number of life events; 2) NEG = sum of negative weightings; and 3) POS = sum of positive weightings. Only the TOTAL score will be used in the analyses as previous research has demonstrated no differences in the predictive utility of frequency of life events versus impact (Grant, Sweetwood. Gerst. \& Yager, 1978; Rowlinson \& Felner, 1988). Two studies have been conducted examining the test-retest reliability. Correlations obtained for the TOTAL score were .63 and .64 . The authors argued that the reliability coefficients were an underestimate given that subjects may have experienced some event during the fiveweek time lag between repeat administrations of the measure (Sarason, et al., 1978).

Profile of Mood States (POMS). The POMS (McNair, Lorr, \& Droppleman. 1992) is a 65 -item adjective-rating scale used to measure affective states occurring over the past week. Responders rate each adjective on a 5-point intensity scale from $0=$ "not at all" to $4=$ "extremely". This measure was developed to assess mood as a state variable as it is sensitive to fluctuating affective states. Factor analysis 
identified six mood states including Tension-Anxiety, Depression-Dejection, AngerHostility, Vigor-Activity, Fatigue-Inertia, and Confusion-Bewilderment. Because the purpose of the study is to examine the mechanism by which exercise exerts its influence, and since depression and anxiety are the most extensively studied psychological variables in the exercise literature, only the Depression-Dejection (DD) factor and Tension-Anxiety (TA) factor were used in this study. The POMS was chosen over the Beck Depression Inventory (BDI) and the State/Trait Anxiety Inventory (STAI) due to its emphasis on fluctuating affective states as opposed to identifying levels of depression and anxiety. Additionally, it will provide more variability than the BDI and STAI for a nonclinical sample. The DD factor has been demonstrated to have adequate concurrent validity with the BDI $(r=.61)$ and excellent internal consistency $(K R 20=.95)$. The TA factor has been show to have high concurrent validity with the Taylor Manifest Anxiety Scale $(r=.80)$ and excellent internal consistency $(\mathrm{KR20}=.92)$. Test-retest has been estimated to be greater than .74 on the DD factor and .70 on the TA factor. This correlation was obtained from intake and pretreatment POMS scores over a medium time of 20 days, and the authors postulated this may be a lower bound estimate of reliability due to the potential change in emotional state associated with finding a source of treatment. The POMS has been used extensively in spons and exercise research (see LeUnes, Hayword, \& Daiss, 1988, for review).

Modified Wahler Physical Symptoms Inventory (WPSI). The WPSI (Wahler. 1983 ) is a self-report measure of physical complaints and symptoms. In the standard 
administration, subjects indicate how often, they are bothered by a symptoms from 0 $=$ almost never to $5=$ nearly everyday. The scale yields a SUM/FREQ score which equals the sum of the weightings and the number of items endorsed. To provide a range of variability, only the SUM score was used in this study. The internal consistency of the test is quite high (KR20s from .88 to .94). It also possesses good test-retest reliability with .94 for one-day delay and .64 for a three month delay.

The WPSI examines health as a trait variable as it emphasizes the assessment of a person's usual physical complaints. The emphasis for the present study is to examine physical symptoms that occurred during the past week, thus treating physical complaints as a fluctuating or state variable. No standardized instrument could be located that examines physical symptoms in this manner. Therefore, a modified version of the WPSI was developed. The Modified WPSI asked "How much did bother you in the past week?" with $0=$ not at all to $5=$ extremely. The scale has been used in this manner in previous research (Jones, 1988).

Maximum Oxygen Consumed (est.VO2max). VO2max refers to the greatest rate of oxygen utilization attainable during strenuous activity. VO2max is measured to provide an index of cardiorespiratory fitness (CRF).

VO2max was estimated using Bruce protocol. Subjects began walking on a treadmill at $2.5 \mathrm{mph}$ with $\mathbf{0}$ degrees incline. The speed and incline were increased at each stage by $2.0 \mathrm{mph}$ and 1.5 degrees respectively. Each stage lasted 3 minutes. Maximum level to which the subject advances depends on fitness level. 
Subjects continued until voluntary volitional exhaustion. The last stage completed by the subject was used to estimate VO2max. Hear rate response to Bruce protocol was measured.

Pbysical Activity Questionnaire. The Physical Activity Questionnaire (Kriska et al., 1990) is a physical activity assessment instrument designed to assess historical, past-year, and past week leisure and occupational activity. Reliability has been demonstrated with adequate test-retest reliability (Spearman's rank-order correlations ranging from .62 to .96 for leisure and occupational activity). Validity of the past week leisure activity has been shown with the Caltrac activity monitor (Spearman's rank order correlation $=.62$ ). Only the past week leisure activity portion was used because the purpose of this study is to examine physical activity related to exercise. Additionally, the one week interval is consistent with the time frame of the other measures. By calculating the product of hours per week engaging in a particular activity and the established MET value for the given activity, a kilocalorie (kcal) score was derived. Because MET is estimated to be one kcal/ kilogram (kg) body weight/ hour, the sum of the products equals $\mathrm{kcal} / \mathrm{kg} /$ week. When divided by $\mathrm{kg}$ body weight, the estimate of energy expenditure is in $\mathbf{k c a l} /$ week.

General Health Ouestionnaire (GHO). The GHQ is a 28 -item self-report questionnaire used as a screening measure of psychological distress. A common considered cut-off to warrant a diagnostic interview is five or more positive answers (Gage \& Leidy, 1991). Vieweg and Hedlund (1983) reported that the internal 
consistency of the GHQ ranged from .78 to .95 and test-retest estimates were between .51 and .90 .

Demographic Ouestionnaire. This questionnaire included questions regarding participants' age, sex, race, education level, employment, medical diagnoses, current medications, and tobacco, alcohol, and caffeine use (see Appendix B). Procedure

At the beginning of the session, subjects were screened for contraindications to exercise testing such as unstable angina, uncontrollable dysthythmia, any serious systemic disorder, acute infection, resting diastolic over $120 \mathrm{~mm} \mathrm{Hg}$, resting systolic over $200 \mathrm{~mm} \mathrm{Hg}$, uncontrollable metabolic disease, recent acute myocardial infarction, or neuromuscular, musculoskeletal, and rhematoid disorders (ACSM, 1988). Those individuals not passing the screen were not given the opportunity to participate. Subjects also completed the GHQ which provided a general indicator of overall emotional distress of the sample. Those participants endorsing either critical items and suicidality or a large number of items were individually interviewed and provided with a referral to the Psychological Services Center. Participants underwent a submaximal exercise tolerance test to estimate VO2max, caliber test, stretch test, and test of muscular strength and endurance. Subjects also completed the WSI, LES. POMS, WPSI, Physical Activity questionnaire, and a demographic questionnaire. Subjects were then dismissed and later mailed feedback on the assessment. 


\section{RESULTS AND DISCUSSION}

\section{Results}

One hundred-thirty-five participants were recruited for this study. One person was exclude and not given the opportunity to participate due to detected heart murmur, and it was recommended that the subject obtain a physician's evaluation. Three subjects were individually interviewed and referred to the Psychological Services Center due to endorsement of critical items or a high number of items on the GHQ. These subjects were allowed to participate in the study.

Simple statistics, including descriptive and frequency analyses, were computed on the demographic variables to provide information about the subject pool. The mean age of subjects was 22.07 years $\left(\underline{s . d_{2}}=4.39\right)$, and their mean year in college was 3.31 years $(\underline{s . d .}=1.30) .55 .2 \%$ of the sample was female, $70.9 \%$ were Caucasian, and $49.3 \%$ were unemployed. Mean score on the GHQ was 2.32 (s.d. $=$ 2.72) indicating a nonclinical sample. These data are presented in Table 1. Descriptive statistics also were computed on all independent and dependent variables and are displayed in Table 2 .

$T$ tests were computed on the demographic variable SEX to determine if there were sex differences on the outcome variables Depression-Dejection (DD), TensionAnxiety (TA), and Wahler sum score (SUM). No significant differences were found between sexes on any of the dependent variables. Additionally, RACE was divided into three groups including Caucasian, African American, and Other. One-way ANOVAs were computed to determine if there were racial differences on scores on 


\section{Table 1}

Simple Statistics: Demographic Variables

\begin{tabular}{|c|c|c|c|c|c|}
\hline Variable & $\mathbf{N}$ & $\%$ & Mean & Range & S.D. \\
\hline Age & 134 & & 22.07 & $17-47$ & 4.39 \\
\hline Year in College & 132 & & 3.31 & 1.7 & 1.30 \\
\hline GHQ & 134 & & 2.32 & $0-12$ & 2.72 \\
\hline Sex & & & & & \\
\hline $\begin{array}{l}\text { Male } \\
\text { Female }\end{array}$ & $\begin{array}{l}60 \\
74\end{array}$ & $\begin{array}{l}44.8 \\
55.2\end{array}$ & & & \\
\hline Race & & & & & \\
\hline $\begin{array}{l}\text { Caucasian } \\
\text { African American } \\
\text { Hispanic } \\
\text { Asian } \\
\text { Indian } \\
\text { Biracial }\end{array}$ & $\begin{array}{r}95 \\
24 \\
4 \\
9 \\
1 \\
1\end{array}$ & $\begin{array}{r}70.9 \\
17.9 \\
3.0 \\
6.7 \\
0.7 \\
0.7\end{array}$ & & & \\
\hline $\begin{array}{l}\text { Employment } \\
\text { Unemployed } \\
\text { Part-time } \\
\text { Full time }\end{array}$ & $\begin{array}{c}66 \\
62 \\
6\end{array}$ & $\begin{array}{c}49.3 \\
46.3 \\
4.5\end{array}$ & & & \\
\hline
\end{tabular}


Table 2

Descriptive Statistics on Independent and Dependent Variables

\begin{tabular}{lccc} 
Variable & Mean & Range & S.D. \\
\hline DD & 8.38 & $0-28$ & 7.29 \\
TA & 9.95 & $1-28$ & 5.76 \\
SUM & 15.94 & $0-69$ & 12.33 \\
LES & 8.93 & $0-27$ & 5.36 \\
EVENT & 30.21 & $0-84$ & 14.47 \\
VO2max & 46.11 & $23.01-81.01$ & 10.91 \\
LPA & 3327.46 & $0-39329.16$ & 4583.81
\end{tabular}


DD, TA, and SUM. No significant differences were found between groups on any of the dependent variables. Furthermore, a correlation matrix was generated with AGE and DD, TA, and SUM. AGE was not significantly correlated with any of the outcome variables, and the obtained correlations were $.0938, .0902$, and .0589 . respectively $(\theta>.05)$.

Hierarchical multiple regression analyses was used to predict the dependent variables DD, TA, and SUM. Predictor variables included LES, EVENT, VO2max, LPA (leisure physical activity), VO2max*EVENT and LPA*EVENT. Due to multicollinearity between EVENT and IMPACT $(I=.84, \mathrm{p}<.001$ ), only EVENT was used in these analyses (Cohen \& Cohen, 1983). Separate regression equations were run on each dependent variable. For each regression, LES was entered in step 1 to control for the effects of major life events. EVENT was entered on step 2 to test for incremental variance above that accounted for by LES. Next, the main effects VO2max and LPA were entered. Finally, the interaction terms VO2max*EVENT and LPA*EVENT were entered. For each regression equation, the residuals were analyzed for outliers greater than 3 standard deviations from the mean and removed from subsequent analyses.

To test hypotheses 1 and 2 examining the incremental variance accounted for by EVENT above that accounted for by LES, each regression equation was examined at step 2. With DD as the dependent variable, the model was significant, $F(2,125)$ $=15.19, \mathrm{p}<.001$. LES and EVENT accounted for $19.55 \%$ of the variance in DD with EVENT adding $4.07 \%$ incremental variance above that accounted for by LES. 
With TA as the outcome variable, the model also was significant, $F(2,127)=9.05$, $\mathrm{p}<.001$. LES and EVENT accounted for $12.48 \%$ of the variance in TA with EVENT adding $4.49 \%$ incremental variance above that accounted for by LES. Finally, with SUM as the dependent variable, the model was significant, $\mathrm{E}(2,124)=$ 17.12. $\mathrm{p}<.001$. LES and EVENT accounted for $21.64 \%$ of the variance in SUM with EVENT adding $16.54 \%$ incremental variance above that accounted for by LES. LES was no longer a significant predictor once EVENT was added into the equation. These results can be seen in Table 3 .

To test hypotheses 3 and 4, SUM was regressed on the predictor variables. Analysis of the residuals indicated three outliers so the analyses were run with the outliers excluded. Results indicated the overall model was significant, $F(120,6)=$ 8.45. $\mathrm{p}<.001$. Results also indicated a significant EVENT*LPA interaction, $(t=$ 3.404, $\mathrm{p}<.001)$. The EVENT $*$ VO2max interaction was not significant. Results are presented in Table 4.

To test hypothesis 5 and research question 6, TA was regressed on the predictor variables. Results indicated the overall model was significant, $F(123,6)=$ 4.379, D $<.001$. Results also indicated a significant EVENT*LPA interaction accounting for $4.59 \%$ incremental variance $(\mathrm{l}=-2.296, \mathrm{Q}<.05)$. The EVENT*VO2max interaction was not significant. Results are presented in Table 5.

To further test hypothesis 5 and research question 6, DD was regressed on the predictor variables. Analysis of the residuals indicated two outliers so subsequent analyses were run with the outliers excluded. Results indicated the overall model was 
Table 3

Hierarchical Multiple Regressions Examining LES and EVENT

Dependent Variable: DD

Multiple R

$\mathbf{R}^{2}$

$\mathbf{R}^{2}$ change

Variable

LES

EVENT
.4422

.1955

.0407
Regression

Residual

$$
F=15.19101
$$

$\mathbf{T}$

3.379

2.514

Sip T

.0010

.0132 df

2

125

Sign $F=.0000$

Beta

.299254

.222598

Dependent Variable: TA

Multiple R

$\mathbf{R}^{2}$

$\mathbf{R}^{2}$ change

.3532

.1248

.0449

Variable

LES

EVENT
Beta

.184929

.233323
Regression

Residual

$$
F=9.05035
$$

Sig T

$\mathbf{T}$

2.023

2.553

.0451

.0119 $\frac{\mathrm{df}}{2}$

127

Sign $F=.0002$

\section{Dependent Variable: SUM}

$\begin{array}{ll}\text { Multiple R } & .4652 \\ \mathrm{R}^{2} & .2164 \\ \mathrm{R}^{2} \text { change } & .1654\end{array}$

Regression

$\frac{\mathrm{df}}{2}$

Residual

2

124

$$
F=17.12010 \quad \text { Sign } F=.0000
$$

Variable

Beta

I

Sip T

LES

.039673

.454

.6507

EVENT

.222598

5.117

.0000 
Table 4

Hierarchical Multiple Regression: SUM as Dependent Variable

\begin{tabular}{llllllll} 
Step & MultR & $\mathbf{R}^{2}$ & F(Eqn) & SignF & R $^{2}$ Change & FChange & SigChange \\
\hline 1 & .2257 & .0509 & 6.709 & .011 & .0509 & 6.709 & .011 \\
2 & .4652 & .2164 & 17.120 & .000 & .1654 & 26.180 & .000 \\
3 & .4758 & .2264 & 8.924 & .000 & .0100 & 0.787 & .458 \\
4 & .5450 & .2970 & 8.449 & .000 & .0706 & 6.027 & .003
\end{tabular}

Variables in the Equation

$\begin{array}{lccc}\text { Variable } & \text { Beta } & \text { T } & \text { SigT } \\ \text { LES } & .0280 & 0.330 & .7423 \\ \text { EVENT } & .8955 & 2.505 & .0136 \\ \text { LPA } & .1669 & 1.494 & .1379 \\ \text { VO2max } & .1086 & 0.628 & .5314 \\ \text { EVENT*LPA } & -.4799 & -3.404 & .0009 \\ \text { EVENT*VO2max } & -.1892 & -0.473 & .6372\end{array}$


Table 5

Hierarchical Multiple Regression: TA as Dependent Variable

\begin{tabular}{llllllll} 
Step & MultR & $\mathbf{R}^{2}$ & $\mathrm{~F}($ Eqn) & SignF & $\mathbf{R}^{2}$ Change & FChange & SigChange \\
\hline 1 & .2826 & .0798 & 11.106 & .001 & .0798 & 11.106 & .001 \\
2 & .3532 & .1247 & 9.050 & .000 & .0449 & 6.516 & .012 \\
3 & .3607 & .1301 & 4.673 & .002 & .0053 & 0.383 & .682 \\
4 & .4195 & .1760 & 4.379 & .000 & .0459 & 3.429 & .036
\end{tabular}

Variables in the Equation

$\begin{array}{llll}\text { Variable } & \text { Beta } & T & \text { Sig } T \\ \text { LES } & .1605 & 1.765 & .0800 \\ \text { EVENT } & .8660 & 2.260 & .0256 \\ \text { LPA } & .2002 & 1.672 & .0970 \\ \text { VO2max } & .1371 & 0.734 & .4646 \\ \text { EVENT*LPA } & -.3441 & -2.296 & .0234 \\ \text { EVENT*VO2max } & -.4846 & 0.002 & .2623\end{array}$


significant, $\mathrm{E}(121.6)=7.297, \mathrm{p}<.001 ;$ however, the interaction terms were not significant (see Table 6). Analysis of the main effects model indicated it was significant, $\mathrm{E}(4,123)=9.727, \mathrm{p}<.001$. Results indicated that LPA and VO2max uniquely contributed a significant amount of the variance in DD $(t=2.032, \mathrm{p}<.05$, and $\underline{t}=-2.225, \mathrm{p}<.05$, respectively), and together accounted for $4.48 \%$ incremental variance above that accounted for by LES and EVENT (see Table 7). Discussion

This study examined exercise as a moderator of the stress-illness relation by exploring leisure physical activity and aerobic fitness as "buffers" of the effects stress has on physical and psychological symptoms in a sample of 135 college students. Specifically, the goal was to provide information regarding the mechanisms by which exercise exhibits its "buffering effects" against minor stress. It was questioned as to whether both increased aerobic fitness associated with exercise and actual participation in the activity itself were necessary for the apparent buffering effects exercise has on stress or is one factor more important than the other. Results suggested that participating in leisure physical activity as opposed to improving aerobic fitness is the mechanism by which exercise exerts its "buffering effect" against physical symptoms and anxiety in response to stress.

Regression analyses were conducted to confirm existing data regarding the predictive utility of minor life events on physical and psychological health and to provide the rationale for examining the moderating effects of exercise on minor life events as opposed to major life events. It was hypothesized (hypotheses 1 and 2) that 
Table 6

Hierarchical Multiple Regression: DD as Dependent Variable

\begin{tabular}{llllllll} 
Step & MultR & $R^{2}$ & F(Eqn) & SignF & $R^{2}$ Change & FChange & SigChange \\
\hline 1 & .3935 & .1549 & 23.090 & .000 & .1549 & 23.090 & .000 \\
2 & .4422 & .1955 & 15.191 & .000 & .0407 & 6.318 & .013 \\
3 & .4902 & .2403 & 9.727 & .000 & .0448 & 3.625 & .030 \\
4 & .5155 & .2657 & 7.297 & .000 & .0254 & 2.091 & .128
\end{tabular}

Variables in the Equation

$\begin{array}{llll}\text { Variable } & \text { Beta } & T & \text { Sig T } \\ \text { LES } & .267753 & 3.085 & .0025 \\ \text { EVENT } & .826837 & 2.284 & .0241 \\ \text { LPA } & .283705 & 2.483 & .0144 \\ \text { VO2max } & -.030828 & 0.171 & .8642 \\ \text { EVENT*LPA } & -.219645 & -1.540 & .1261 \\ \text { EVENT*VO2max } & -.512228 & -0.439 & .2155\end{array}$


Table 7

Hierarchical Multiple Regression: Analysis of Main Effects with $\mathrm{DD}$ as Dependent Variable

\begin{tabular}{|c|c|c|c|}
\hline \multirow[t]{2}{*}{$\begin{array}{l}\text { Multiple } \mathbf{R} \\
\mathbf{R}^{2} \\
\mathbf{R}^{1} \text { Change }\end{array}$} & $\begin{array}{l}.4902 \\
.2403 \\
.0448\end{array}$ & $\begin{array}{l}\text { Regression } \\
\text { Residual } \\
F=9.72693\end{array}$ & $\begin{array}{c}\frac{\mathrm{df}}{6} \\
121 \\
\text { Sign } F=.0000\end{array}$ \\
\hline & \multicolumn{3}{|c|}{ Variables in the Equation } \\
\hline Variable & Beta & $\underline{T}$ & Sig $T$ \\
\hline LES & .283973 & 3.262 & .0014 \\
\hline EVENT & .264683 & 2.984 & .0034 \\
\hline LPA & .165156 & 2.032 & .0443 \\
\hline $\mathrm{VO} 2 \max$ & -.184571 & -2.225 & .0279 \\
\hline
\end{tabular}


minor life events would add significant incremental variance to the prediction of mood and physical symptoms report above that accounted for by major life events. Results were consistent with previous research (e.g. Thomason et al., 1992; Eckenrode, 1984 ) indicating minor life events provided significant incremental variance above that accounted for by major life events on both psychological symptoms including depression and anxiety and physical symptoms report. This was further supported by the loss of significant predictability by major life events in physical symptoms report once minor life events was entered into the equation.

It was hypothesized (hypothesis 3 ) that after controlling for the effects of major life events, leisure physical activity would moderate the effects minor stress had on physical symptoms report. Results were consistent with this hypothesis such that those participants experiencing higher levels of minor stress and engaging in lower levels of physical activity experienced more physical symptoms than individuals with higher levels of minor stress and higher levels of physical activity. It also was hypothesized (hypothesis 4) that after controlling for the effects of major life events, aerobic fitness would moderate the effects minor stress had on physical symptoms report; however, results indicated no moderating effect for aerobic fitness. Together. these results suggest that participating in leisure physical activity as opposed to improving aerobic fitness is the mechanism by which exercise exerts its "buffering effect" against physical symptoms in response to stress. These results are consistent with the Centers for Disease Control and Prevention's recent change in the conceptualization of exercise from an "exercise-fitness" model to a "broader physical 
activity-health paradigm" (Pate et al., 1995). Evidence suggests that the health benefits of physical activity increase in proportion to the total amount of activity as opposed to the manner in which it is performed, i.e., intensity, mode. Likewise, results of this study indicated that the protective effects against stress also are higher with higher levels of participation in leisure physical activity.

These results also are consistent with the lack of conclusive support for the "fitness hypothesis", which has led researchers to question its sufficiency in explaining the benefits of exercise. Because the literature indicates aerobic fitness can only improve by $15-20 \%$ with aerobic exercise training (ASCM, 1988), perhaps there are other physiological changes, not assessed by aerobic fitness, that result with increased physical activity causing an improvement in the body's ability to combat stress, i.e, decreased report of physical symptoms.

It was hypothesized (hypothesis 5) that after controlling for the effects of major life events, leisure physical activity would moderate the effects minor stress has on mood. Results were consistent with this hypothesis for anxiety such that those participants experiencing higher levels of minor stress and engaging in lower levels of physical activity experienced more negative anxiety scores. With regards to the moderating effect of aerobic fitness on anxiety, there was no a priori hypothesis (research question 6) given that the literature has provided mixed results regarding the effects of fitness on mood. Results indicated no moderating effect for aerobic fitness. Collectively, these results are consistent with those related to physical health and suggest that participating in leisure physical activity as opposed to improving aerobic 
fitness is the mechanism by which exercise exerts its "buffering effect" against anxiety in response to stress. A recent study by Thirlaway and Benton (1992) supports these findings and suggests that the mental health benefits of exercise are a result of participating in physical activity instead of increased fitness. These researchers examined the relations among fitness, physical activity, and mood. Results indicated a significant activity by fitness interaction such that higher levels of fitness and lower levels of activity were associated with more negative mood. There was no association between fitness and mood in individuals who were moderately active or active indicating participation in physical activity is the factor associated with better mood.

These results also compliment existing literature that has demonstrated improvements in state anxiety are short-term (Berger et al., 1988). Temporary changes in anxiety following exercise supports the idea that engaging in leisure physical activity as opposed to fitness improvements is the key to exercise benefits. Results of this study fail to advance the literature in terms of confirming one specific theoretical hypothesis concerning the tranquilizing effects of exercise. However, results are consistent with existing theories including biological theories implicating the increase in circulating catecholamines or rise in brain temperature following exercise resulting in a relaxed state (deVries, 1987). Findings also support psychological theories which suggest that exercise reduces the impact of stress by providing distraction from stressful stimuli (Morgan, 1987). 
Results regarding the moderating effect of leisure physical activity on depression were inconsistent with the above hypothesis and indicated no moderating effect. As with anxiety, there was no a priori hypothesis with regards to the moderating effect of aerobic fitness on depression given that the literature has provided mixed results regarding the effects of fitness on mood. Results indicated that for depression, there also was no moderating effect for aerobic fitness. Analysis of the main effects; however indicated that the combination of leisure physical activity and aerobic fitness together predicted depression after controlling for the effects of both major and minor life events. These results suggest that regardless of level of stress, the combination of these two variables predict mood. Due to the correlational nature of this analysis, definitive statements regarding causality cannot be made, and it may be that depressed individuals are less likely to be physically active and aerobically fit. However, results of treatment outcome studies support the notion that exercise does affect depression (e.g., Sime, 1987).

The overall data examining mood provided interesting results in that there was a moderating effect for leisure physical activity on anxiety but not on depression. It could be that more of a "buffering effect" would be obtained in a clinically depressed population. Additionally, it may be that a more complex mechanism than was analyzed in this study, i.e., stress by aerobic fitness by physical activity interaction, is responsible for the "buffering effects" against depression, such as the one obtained in Thirlaway and Benton (1992) study mentioned above (activity by fitness interaction). 
Collectively, the results of this study lend support to the notion that the "stress-buffering" effect of exercise is a result of engaging in leisure physical activity. These results are consistent with the public health recommendation to increase physical activity for physical health benefits and adds information regarding potential mental health benefits, particularly anxiety reduction, for regular physical activity participation. Given that this is a nonclinical example, whether comparable results would be obtained in clinically distressed individuals remains an empirical question. Because studies have indicated improvements in mood following participation in exercise programs with no significant improvements in fitness (e.g., Sime, 1987), the notion that comparable results may be found in clinical samples is supported.

A promising aspect of these results is that they indicate mental health benefits in an overall non-clinical sample. In a review, Martinsen and Stephens (1994) noted the lack of studies examining mental health benefits in non-clinical populations. These authors suggested that evidence for mental health promotion in non-clinical populations will strengthen the rationale for exercise adherence. Additionally, this study adds to existing literature supporting the examination of minor life events in the prediction of mental and physical health problems. Furthermore, the examination of both aerobic fitness and physical activity allowed for information to be obtained regarding their unique contributions to the "buffering effects" against stress when examined together as opposed to only studying one of these variables at a time.

Research suggests that regular activity is necessary for the maintenance of physical health benefits obtained from exercise (Fletcher et al, 1992). It would reason 
to believe from these results that this finding would hold for the stress "buffering effect" of leisure physical activity as well, given the unpredictable nature of stress. Fortunately, because the emphasis has changed to increasing physical activity as opposed to engaging in exercise with the goal of improving fitness, more individuals, including the elderly and chronically ill, may be able to obtain both the physical and mental health benefits of engaging in regular physical activity.

In summary, results of this study suggest that engaging in leisure physical activity, as opposed to increasing aerobic fitness, is the factor associated with the "stress-buffering" effect exercise has on physical symptoms and anxiety. Given the cross-sectional nature of this study, future longitudinal research is necessary to support the efficacy of leisure physical activity in moderating the stress-illness relation. Additionally, research indicates that the greatest physical health benefits are obtained from progressing from a sedentary lifestyle to one of moderate intensity physical activity (Pate et al., 1995). It would be useful to advance this understanding of exercise dose to determine the amount of physical activity necessary for the greatest mental health benefits. Furthermore, research in clinical populations may provide additional information regarding the mechanisms involved in providing the beneficial effects of exercise. 


\section{REFERENCES}

American College of Sports Medicine. (1988). Resource Manual for Guidelines for Exercise Testine and Prescription. Philadelphia: Lea and Febiger.

Bandura, A. (1989). Human agency in social cognitive theory. American Psychologist, 44. 1175-1184.

Bandura, A. (1977). Self-efficacy: Toward a unifying theory of behavioral change. Psychological Review, 2, 191-215.

Baron, R.M., \& Kenny, D.A. (1986). The moderator-mediator variable distinction in social psychological research: Conceptual, strategic, and statistical considerations. Journal of Personality and Social Psychology, 51, 1173-1182.

Berger, B.G., Friedmann, E., \& Eaton, M. (1988). Comparison of jogging, the relaxation response, and group interaction for stress reduction. Joumal of Sport \& Exercise Psychology, 10, 431-447.

Billings, A.G., \& Moos, R.H. (1984). Coping, stress, and social resources among adults with unipolar depression. Journal of Personality and Social Psychology. 46, 877-891.

Billings, A.C., \& Moos, R.H. (1982). Stressful life events and symptoms: A longitudinal model. Health Psychology, 2, 99-117.

Blaney, P.H. (1985). Stress and depression: A critical review. In T.M. Field, P.M. McCabe, \& N. Schneiderman (Eds.), Stress and Coping (pp. 263-283). New Jersey: Lawrence Erlbaum Associates.

Bolger, N., DeLongis, A., Kessler, R.C., \& Schilling E.A. (1989). Effects of daily stress on negative mood. Lournal of Personality and Social Psychology, 57. 808-818.

Bouchard, C. (1990). Discussion: Heredity, fitness, and health. In C. Bouchard, R.J., Shephard, T. Stephens, J.R. Sutton, \& B.D. McPherson (Eds.), Exercise, Fitness, \& Health. (pp. 147-153). Champaign. IL: Human Kinetics.

Brantley, P.J., \& Jones, G.N. (1993). Daily stress and stress-related disorders. Annals of Behavioral Medicine, 15. 17-25. 
Brantley, P.J., Jones, G.N., Boudreaux, E., \& Catz, S.L. (in press). The Weekly Stress Inventory. In C.P. Zalaquett (Ed.), Evaluating Stress: A Book of Resources. University Press of America.

Brantley, P.J., Waggoner, C.D., Jones, G.N., \& Rappaport, N.B. (1987). A daily stress inventory: Development, reliability, and validity. Journal of Behavioral Medicine, 10, 61-74.

Brown, J.D. (1991). Staying fit and staying well: Physical fitness as a moderator of life stress. Joumal of Personality and Social Psychology, 60, 555-561.

Brown, J.D., \& Lawton, M. (1986). Stress and well-being in adolescence: The moderating role of physical exercise. Journal of Human Stress, 125-131.

Brown, J.D., \& Siegel, J.M. (1988). Exercise as a buffer of life stress: A prospective study of adolescent health. Health Psychology, 7, 341-353.

Caspi, A., Bolger, N., \& Eckenrode, J. (1987). Linking person and context in the daily stress process. Joumal of Personality and Social Psychology, 52, 194195.

Cinciripini, P.M. (1986a). Cognitive stress and cardiovascular reactivity. I. Relationship to hypertension. American Heart Joumal, 112. 1044-1050.

Cinciripini, P.M. (1986b). Cognitive stress and cardiovascular reactivity. II. Relationship to atherosclerosis, arrhythmias, and cognitive control. American Heart Joumal, 212, 1051-1065.

Clarkson, T.B., Manuck, S.B., \& Kaplan, J.R. (1986). Potential role of cardiovascular reactivity in atherogenesis. In K.A. Matthews, S.M. Weiss, T. Detre, T.M. Dembroski, B. Falkner, S.B. Manuck, \& R.B. Williams (Eds.), Handbook of Stress. Reactivity, and Cardiovascular Disease (pp. 35-47). New York: John Wiley \& Sons.

Claytor, R.P. (1991). Stress reactivity: Hemodynamic adjustments in trained and untrained humans. Medicine and Science in Sports and Exercise, 23 (7), 873 881 .

Cohen, J., \& Cohen, P. (1983). Applied Multiple Regression/Correlation Analysis for the Behavioral Sciences (2nd ed.). New Jersey: Lawrence Erlbaum Associates, Publishers. 
Cohen, S., \& Hoberman, H.M. (1983). Positive events and social supports as buffers of life change stress. Joumal of Apolied Social Psychology, 13, 99 125.

Cohen, S. \& Wils, T.A. (1985). Stress, social support, and the buffering hypothesis. Psycholoqical Bulletin, 98, 310-357.

Cox, R.H. (1991). Exercise training and response to stress: Insights from an animal model. Medicine and Science in Sports and Exercise, 23 (7), 853-859.

Creed. F. (1985). Invited review: Life events and physical illness. Lournal of Psychosomatic Research, 29, $113-123$.

DeLongis, A., Coyne, J.C., Dakof, G., Folkman, S., \& Lazarus, R.S. (1982). Relationship of daily hassles, uplifts, and major life events to health status. Health Psychology, 1, 119-136.

DeLongis, A., Folkman, S., \& Lazarus, R.S. (1988). The impact of daily stress on health and mood: Psychological and social resources as mediators. Journal of Personality and Social Psychology. 54, 486-495.

Derogatis, L.R., \& Coons, H.L. (1993). Self-repon measures of stress. In L. Goldberger \& S. Breznitz (Eds.). Handbook of Stress: Theoretical and Clinical Aspects (2nd ed.), (pp.685-705). New York: The Free Press.

deVries, H.A. (1987). Tension reduction with exercise. In W.P. Morgan \& S.E. Goldston (Eds.), Exercise and Mental Health (pp. 99-104). Washington: Hemisphere Publishing Corporation.

Dimsdale, J.E., \& Moss, J. (1980). Plasma catecholamines in stress and exercise. Joumal of the American Medical Association, 243, 340-342.

Dimsdale, J.E., Young. D., Moore, R., \& Strauss, H.W. (1987). Do plasma norepinephrine levels reflect behavioral stress? Psychosomatic Medicine, 49 , 375-382.

Dishman, R.K. (1985). Medical psychology in exercise and sport. Medical Clinics of North America, 69, 123-143.

Dohrenwend, B.S., \& Dohrenwend, B.P. (1974). A brief historical introduction to research on stressful life events. In B.S. Dohrenwend, \& B.P. Dohrenwend (Eds.), Stressful Life Events: Their Nature and Effects (pp. 1-5). New York: John Wiley \& Sons. 
Eckenrode, J. (1984). Impact of chronic and acute stressors on daily reports of mood. Journal of Personality and Social Psychology. 46, 907-918.

Engel, B.T. (1985). Stress is a noun! No, a verb! No, an adjective! In T.M. Field, P.M. McCabe, \& N. Schneiderman, (Eds.) Stress and Coping, (pp. 312). New Jersey: Lawrence Erlbaum Associates, Publishers.

Everly, G.S., Jr. (1987). The Assessment of the Human Stress Response. New York: AMS Press Inc.

Fletcher, G.F., Blair, S.N., Blumenthal, J., Caspersen, C., Chaitman, B., Epstein, S., Falls, H., Sivarajan Froelicher, E.S., Froelicher, V.F., \& Ping, 1.L. (1992). Statement on exercise: Benefits and recommendations for physical activity programs for all Americans. Circulation. 86, 340-344.

Folkman, S., Lazarus, R.S., Gruen, R., \& DeLongis, A. (1986). Appraisal, coping. health status, and psychological symptoms. Journal of Personality and Social Psychology, 50, 571-579.

Gage, L.W., \& Leidy, N.K. (1991). Screening for psychosocial distress: Implications for prevention and health promotion. Bublic Health Nursing, $\underline{8}$. 267-275.

Garrett, V.D., Brantley, P.J., Jones, G.N., \& McKnight, G.T. (1991). The relation between daily stress and Crohn's Disease. Joumal of Behavioral Medicine. 14, 87-96.

Goetsch, V.L., Wiebe, D.J., Veltum, L.G., \& Van Dorsten, B. (1990). Stress and blood glucose in Type Il diabetes mellitus. Behaviour Research and Therapy. 28, 531-537.

Goreczny, A.J., Brantley, P.J., Buss, R.R., \& Waters, W.F. (1988). Daily stress and anxiety and their relation to daily fluctuations of symptoms in asthma and chronic obstructive pulmonary disease (COPD) patients. Journal of Psychopathology and Behavioral Assessment, 10, 259-267.

Grant, L., Sweetwood, H., Gerst, M.S., \& Yager, J. (1978). Scaling procedures in life events research. Joumal of Psychosomatic Research, 22, 525-530.

Gruen, R.J. (1993). Stress and depression: Toward the development of integrative models. In L. Goldberger \& S. Breznitz (Eds.), Handbook of Stress: Theoretical and Clinical Aspects (2nd ed.), (pp. 550-569). New York: The Free Press. 
Halford, W.K., Cuddihy, S., \& Mortimer, R.H. (1990). Psychological stress and blood glucose regulation in Type I diabetic patients. Health Psychology, 2. 516-528.

Hamberger, L.K., \& Lohr, J.M. (1984). Stress and stress management: Research and applications. New York: Springer Publishing Company.

Hammen, C., Mayol, A., DeMayo, R., \& Marks, T. (1986). Initial symptom levels and the life-events depression relationship. Journal of Abnormal Psychology, 95, 114-122.

Herd, J.A. (1986). Neuroendocrine mechanisms in coronary heart disease. In K.A. Matthews, S.M. Weiss, T. Detre, T.M. Dembroski, B. Falkner, S.B. Manuck, \& R.B. Williams (Eds.), Handbook of Stress, Reactivity and Cardiovascular Disease (pp. 49-70). New York: John Wiley \& Sons.

Hobfoll, S.E., \& Vaux, A. (1993). Social support: Social resources and social context. In L. Goldberger \& S. Breznitz (Eds.), Handbook of Stress: Theoretical and Clinical Aspects (2nd ed.), (pp. 685-705). New York: The Free Press.

Holmes, D.S. (1993). Aerobic fitness and the response to psychological stress. In P. Seraganian (Ed.), Exercise Psychology: The Influence of Physical Exercise on Psychological Prosesses (pp. 39-63). New York: John Wiley \& Sons, Inc.

Holmes, D.S., \& Roth, D.L. (1985). Association of aerobic fitness with pulse rate and subjective responses to psychological stress. Psychophysiology, 22 (5) 525-529.

Hull, E.M., Young, S.H., \& Ziegler, M.G. (1984). Aerobic fitness affects cardiovascular and catecholamine responses to stressors. Psychophysiology, 21 (3), 353-360.

Jandorf, L., Deblinger, E., Neale, J.M., \& Stone, A.A. (1986). Daily versus major life events as predictors of symptom frequency: A replication study. The Journal of General Psychology, 113. 205-218.

Jones, G.N. (1988). The Relation Between Daily Stress and Health. Unpublished doctoral dissertation.

Kamarck, T.W., Jennings, R., Stewart, C.J., \& Eddy, M.J. (1993). Relable responses to a cardiovascular reactivity protocol: A replication study in a biracial female sample. Psychophysiology, 30, 627-634. 
Kanner, A.D., Coyne, J.C., Schaefer, C., \& Lazarus, R.S. (1981). Comparisons of two models of stress measurement: Daily hassles and uplifts versus major life events. Joumal of Behavieral Medicine, 4, 1-39.

Kasprowicz, A.L., Manuck, S.B., Malkoff, S.B., \& Krantz, D.S. (1990). Individual differences in behaviorally evoked cardiovascular response: Temporal stability and hemodynamic patterning. Psychophysiology, 27, 605619.

Katkin, E.S., Dermit, S., \& Wine, S. K. (1993). Psychophysiological assessment of stress. In L. Goldberger \& S. Breznitz (Eds.), Handbook of Stress: Theoretical and Clinical Aspects, (2nd ed.) (pp. 142-157). New York: The Free Press.

Krantz, D.S., \& Manuck, S.B. (1984). Acute psychophysiologic reactivity and risk of cardiovascular disease: A review and methodologic critique. Psychological Bulletin. 26, 435-464.

Kriska, A.M., Knowler, W.C., LaPorte, R.E., Drash, A.L., Wing, R.R., Blair, S.N., Bennett, P.H., \& Kuller, L.H. (1990). Development of questionnaire to examine relationship of physical activity and diabetes in Pima Indians. Diabetes Care, 13, 401-408.

Kubitz, K.A., \& Landers, D.M. (1993). The effects of aerobic training on cardiovascular responses to mental stress: An examination of underlying mechanisms. Journal of Sport \& Exercise Psychology, 15, 326-337.

Lawrence, R.M. (1983). Psychological aspects of exercise. In A.A. Bove \& D.T. Lowenthal, (Eds.) Exercise Medicine: Physiological Principles and Clinical Applications (pp. 335-345). New York: Academic Press.

Lazarus, R.S. (1993). Why we should think of stress as a subset of emotion. In L. Goldberger \& S. Breznitz (Eds.), Handbook of Stress: Theoretical and Clinical Aspects, (2nd ed.) (pp. 21-39). New York: The Free Press.

Lazarus, R.S. (1984). Puzzles in the study of daily hassles. Joumal of Behavioral Medicine, 7, 375-389.

Lazarus, R.S., \& Folkman, S. (1984). Stress, Appraisal, and Coping. New York: Springer Publishing Company.

LeUnes, A., Hayword, S.A., \& Daiss, S. (1988). Annotated bibliography on the Profile of Mood States in sports, 1975-1988. Joumal of Spon Behavior, 11. 213-240. 
Levor, R.M., Cohen, M.J., Naliboff, B.D., McArthur, D., \& Heuser, G. (1986). Psychosocial precursors and correlates of migraine headache. Journal of Consultine and Clinical Psychology, 347-353.

Lin, N., Simeone, R., Ensel, W.M., \& Kuo, W. (1979). Social suppon, stressful life events, and illness: A model and an empirical test. Joumal of Health and Social Behavior, 20, 108-119.

Long, B.C., \& Haney, C.J. (1988). Coping strategies for working women: Aerobic exercise and relaxation interventions. Behayior Therapy, 19, 75-83.

Manuck, S.B., \& Krantz, D.S. (1986). Psychophysiologic reactivity in coronary heart disease and essential hypertension. In K.A. Matthews, S.M. Weiss, T. Detre, T.M. Dembroski, B. Falkner, S.B. Manuck, \& R.B. Williams (Eds.), Handbook of Stress. Reactivity, and Cardiovascular Disease (pp. 11-34). New York: John Wiley \& Sons.

Martinsen, E.W., \& Stephens, T. (1994). Exercise and mental health in clinical and free-living populations. In R. Dishman (Ed.). Advances in Exercise Adherence (pp. 55-72). Champaign, IL: Human Kinetics.

Martinsen, E.W., Strand, J., Paulsson, g., \& Kaggestad. (1989). Physical fitness level in patients with anxiety and depressive disorders. Intermational Joumal of Sports Medicine, 10, 58-61.

McClure, J., Thomason, B.T., Catz, S., Jones, G., \& Brantley, P. (1993). Prediction of depression in a heterogeneous, low SES, HIV + population: An examination of social support and stress. Poster presented at the convention of the Association for the Advancement of Behavior Therapy, Atlanta, GA.

McNair, D.M., Lorr, M., \& Droppleman, L.F. (1992). Edits Manual for the Profile of Mood States-Revised. San Diego: Educational \& Industrial Testing Service.

Moos, R.H., \& Schaefer, J.A. (1993). Coping resources and processes: Current concepts and measures. In L. Goldberger \& S. Breznitz (Eds.), Handbook of Stress: Theoretical and Clinical_Aspects, (2nd ed.) (pp. 234-257). New York: The Free Press.

Morgan, W.P. (1987). Reduction of state anxiety following acute physical activity. In W.P. Morgan \& S.E. goldston (Eds.). Exercise and Mental Health (pp. 105-109). Washington: Hemisphere Publishing Corporation. 
Morgan, W.P., \& Goldston, S.E. (1987). Introduction. In W.P. Morgan \& S.E. Goldston (Eds.), Exercise and Mental Health (pp. 3-7). Washington: Hemisphere Publishing Corporation.

Mosley, T.H., Penzien, D.B., Johnson, C.A., Brantley, P.J., Wittrock, D.A., Andrew, M.E., \& Payne, T.J. (1991). Time-series analysis of stress and headache. Cephalalgia, 11, 306-307.

Nathan, K.L., Brantley, P.J., Goreczny, A., \& Jones, G.N. (1988). Daily stress, state anxiety, and disease severity in asthma. Poster presented at the annual meeting of the American Psychological Association, Atlanta, GA.

O'Leary, A. (1990). Stress, emotion, and human immune function. Psychological Bulletin, 108, 363-382.

Ouellette, S.C. (1993). Inquiries into hardiness. In L. Goldberger \& S. Breznitz (Eds.), Handboek of Stress: Theoretical and Clinical Aspects, (2nd ed.) (pp. 77-100). New York: The Free Press.

Paffenbarger, R.S., Blair, S.N., Lee. I. \& Hyde, R.T. (1993). Measurement of physical activity to assess health effects in free-living populations. Medicine and Science in Sprots and Exercise. 25, 60-70.

Paffenbarger, R.S., Hyde, R.T., \& Wing, A.L. (1990). Physical activity and physical fitness as determinants of health and longevity. In C.Bouchard, R.J., Shephard, T. Stephens, J.R. Sutton, \& B.D. McPherson (Eds.), Exercise. Fitness, \& Health, (pp. 33-48). Champaign, IL: Human Kinetics.

Pate, R.R., Pratt, M., Blair, S.N., Haskell, W.L., Macera, C.A., Bouchard, C., Buchner, D., Ettinger, W., Heath, G.W., King, A.C., Kriska, A., Leon, A.S., Marcus, B.H., Morris, J., Paffenbarger, R.S., Patrick, K., Pollock, M.L., Rippe, J.M., Sallis, J., \& Wilmore, J.H. (1995). Physical activity and public health: A recommmendation from the Centers for Disease Control and Prevention and the American College of Sports Medicine. IAMA. 5, 402-407.

Potter, W.Z., Grossman, F., \& Rudorfer, M.V. (1993). Noradrenergic function in depressive disorders. In J.J. Mann \& D.J. Kupfer (Eds.), Biology of Derpessive Disorders Pan A: A Systems Perspective, (pp. 1-27). New York: Plenum Press.

Rabkin, J.G. (1993). Stress and psychiatric disorders. In L. Goldberger \& S. Breznitz (Eds.), Handbook of Stress: Theoretical and Clinical Aspects. (2nd ed.) (pp. 477-495). New York: The Free Press. 
Roth, D.L., \& Holmes, D.S. (1985). Influence of physical fitness in determining the impact of stressful life events on physical and psychologic health. Psychosomatic Medicine, 47, 164-173.

Rowlinson, R.T., \& Felner, R.D. (1988). Major life events, hassles, and adaptation in adolescence: Confounding in the conceptualization and measurement of life stress and adjustment revisited. Joumal of Personality and Social Psychology, $55,432-444$.

Saab, P.G., Llabre, M.M., Hurwitz, B.E., Frame, C.A., Reineke, L., Fins, A.I., McCalla, J., Cieply, L.K., \& Schneiderman, N. (1992). Myocardial and peripheral vascular responses to behavioral challenges and their stability in black and white Americans. Psychophysiology. 29, 384-397.

Sandler, I.N., \& Barrera, M. (1984). Toward a multimethod approach to assessing the effects of social support. American Joumal of Community Psychology. 12. 37-52.

Sarason, I., Johnson, J., \& Siegel, J. (1978). Assessing the impact of life changes: Development of the Life Experiences Survey, Journal of Consulting and Clinical Psychology, 5, 932-946.

Selye, H. (1993). The history of the stress concept. In L. Goldberger \& S. Breznitz (Eds.), Handbook of Stress: Theoretical and Clinical Applications. (2nd ed.) (pp. 7-17). New York: The Free Press.

Sime. W.E. (1987). Exercise in the prevention and treatment of depression. In W.P. Morgan \& S.E. Goldston (Eds.), Exercise and Mental Health (pp. 145152). Washington: Hemisphere Publishing Corporation.

Simons, A.D., McGowan, C.R., Epstein, L.H., Kupfer, D.J., \& Robertson, R.J. (1985). Exercise as a treatment for depression: An update. Clinical Psychology Review, 5, 553-568.

Sinyor, D., Golden, M., Steinert, Y., \& Seraganian, P. (1986), Experimental manipulation of aerobic fitness and response to psychosocial stress: Heart rate and self-report measures. Psychosomatic Medicine, 48 (5), 324-337.

Sinyor, D., Schwartz, S.G., Peronnet, F., Brisson, G., \& Seraganian, P. (1983). Acrobic fitness level and reactivity to psychosocial stress: Physiological. biochemical, and subjective measures. Psychosomatic Medicine, 45 (3), 205216. 
Sothmann, M.S. (1991). Catecholamine, behavioral stress, and exerciseintroduction to the symposium. Medicine and Science in Sports and Exercise, 23 (7), 836-838.

Sothmann, M.S., Horn T.S., Hart, B.A., \& Gustafson, A.B. (1987). Comparison of discrete cardiovascular fitness groups on plasma catecholamine and selected behavioral responses to psychological stress. Psychophysiology, 24 (1), 4754.

Spielberger, C.D. (1987). Stress, emotions, and health. In W.P. Morgan \& S.E. Goldston (Eds.), Exercise and Mental Health (pp. 11-16). Washington: Hemisphere Publishing Corporation.

Stein, M., \& Miller, A.H. (1993). Stress, the immune system, and health and illness. In L. Goldberger \& S. Breznitz (Eds.), Handbook of Stress: Theoretical and Clinical Aspects, (2nd ed.) (pp. 127-141). New York: The Free Press.

Thirlaway, K. \& Benton, D. (1992). Participation in physical activity and cardiovascular fitness have differenct effects on mental health and mood. Joumal of Psychosomatic Research, 36, 657-665.

Thomason, B.T., Brantley, P.J., Jones, G.N., Dyer, H.R., \& Morris, J.L. (1992). The relation between stress and disease activity in rheumatoid arthritis. Joumal of Behavioral Medicine, 15. 215-220.

Vieweg, B. \& Hedlund, J. (1983). The general health questionnaire (GHQ): A comprehensive review. Joumal of Operational Psychiatry, 13, 71-72.

Wahler, H.J. (1983). The Wahler Physical Symotoms Inventory Manual. Los Angeles: Western Psychological Services.

Weinberger, M., Hiner, S.L., \& Tierney, W.M. (1987). In support of hassles as a measure of stress in predicting health outcomes. Journal of Behavioral Medicine, 10, 19-31. 


\section{APPENDIXES}

Appendix A: Informed Consent

RESEARCH PROJECT: Lifestyle Evaluation

INVESTIGATORS: Cindy Carmack, Marta Amaral-Melendez, Ed Boudreaux, \& Phillip J. Brantley, Ph.D.

PHONE: 358-1105

\section{INFORMED CONSENT}

I, , freely and willingly consent to be a participant in a research project investigating lifestyle factors with college students As a participant, I agree to undergo a graded exercise tolerance test and to complete several paper and pencil questionnaires.

1 shall perform a graded treadmill exercise test. Exercise will begin at a low level and be advanced in stages. During the test, heart rate and blood pressure will be intermittently monitored.

The test may be stopped at any time because of signs of fatigue. I understand that I may stop the test at any time because of feelings of fatigue or discomfort or for any other personal reason.

I understand that the risks of this testing procedure may include disorders of heart beats, abnormal blood-pressure response, and very rarely, a heart attack.

I understand that by participating in this study, I will receive a health assessment which will include results of the fitness evaluation, stretch test, caliber test, and recommendations regarding caloric intake and physical activity. Additionally, I will receive extra credit in my psychology course for participation.

I understand that I may withdraw from participation in this study at any time with no adverse consequences. I understand that any information I provide during this study will be kept in strict confidence, and if this information is presented publicly (i.e.. conferences, journal articles), no information will be identified with me personally.

I realize that I have a right to ask questions at any time and to have my questions answered to my satisfaction. By signing, I freely provide my consent to participate in the study.

Participant

Witness
Subject Number

\section{Date}


Appendix B: Demographic Questionnaire

\section{DEMOGRAPHIC FORM - LIFESTYLE EVALUATION}

Subject \#:

Height:

Weight:

Age:

Sex:

Race:

Year in college:

Employment:

Medical diagnoses: (check all that apply)

[] High blood pressure

[] Diabetes

[] Heart disease

[] Kidney problems

[] Liver problems

[] Angina

[) Arrhythmia

[l Bone or joint problems

[] Stroke

I] Frequent headaches

[] Asthma

[] Major surgery over the past year

[] Other

[] Psychological problems

On average, how many cigarettes do you smoke per day?

On average, how much alcohol do you consume per week?

Hard liquor (shots or mixed drinks)

Wine (4 oz glass)

Beer ( $12 \mathrm{oz}$ bottles or cans)

On average. how much caffeine do you consume per day?

Coffee

Soft drinks

Tea

List current medications you are taking: 


\section{VITA}

Cindy Lynn Carmack was born October 16, 1967, in Fort Worth. Texas. She attended public schools in Houston, Texas, and graduated from high school in 1986. She earned the degree Bachelor of Science, with a major in Psychology and a minor in Biology, from Texas A \& M University in 1990. She earned her Master of Arts degree in Clinical Psychology from Louisiana State University in 1993. Her clinical psychology internship was at the University of Mississippi Medical Center/ Veteran's Administration Medical Center Consortium in Jackson. Mississippi, in 1994 and 1995. She completed her doctoral training with a major in Clinical Psychology and a minor in Exercise Physiology at Louisiana State University. She currently is working at the Pennington Biomedical Research Center in Baton Rouge, Louisiana. 


\section{DOCTORAL EXAMINATION AND DISSERTATION REPORT}

Candidate: Cindy Lynn Carmack

Mejor Fieldi Psychology

Title of Dienertation: Aeroble Fitness and Lelsure Physical Activity as Moderators of the Stress-tllness Relation

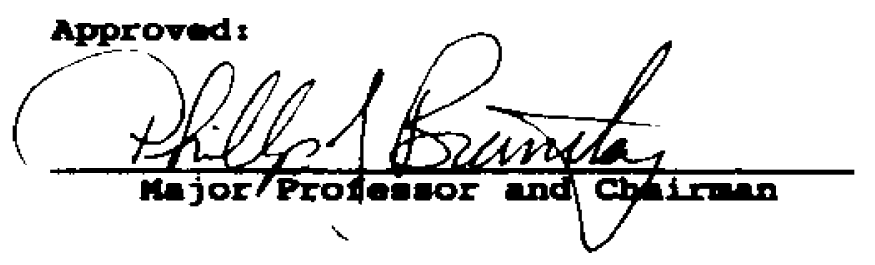

Dean of the Graduate school

EXAMINING COMMITTEE:
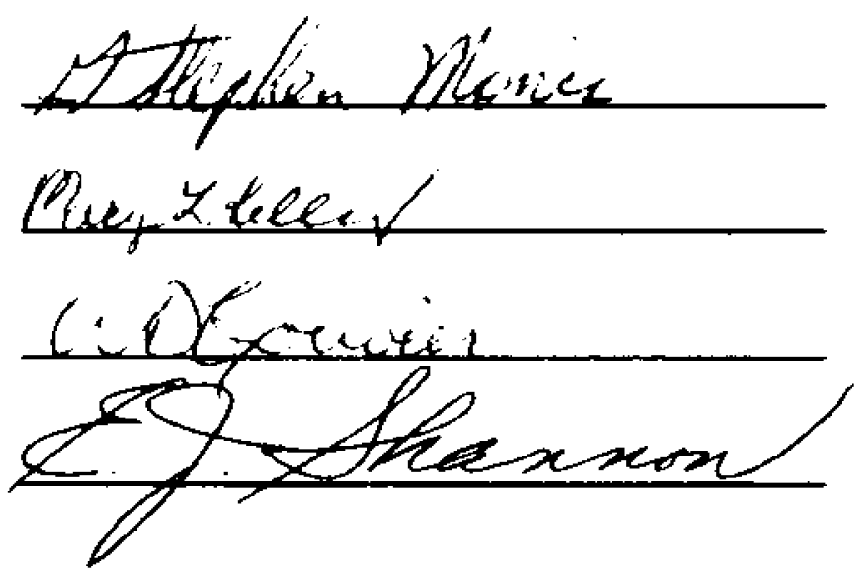

Date of Examination:

November 7,1995 